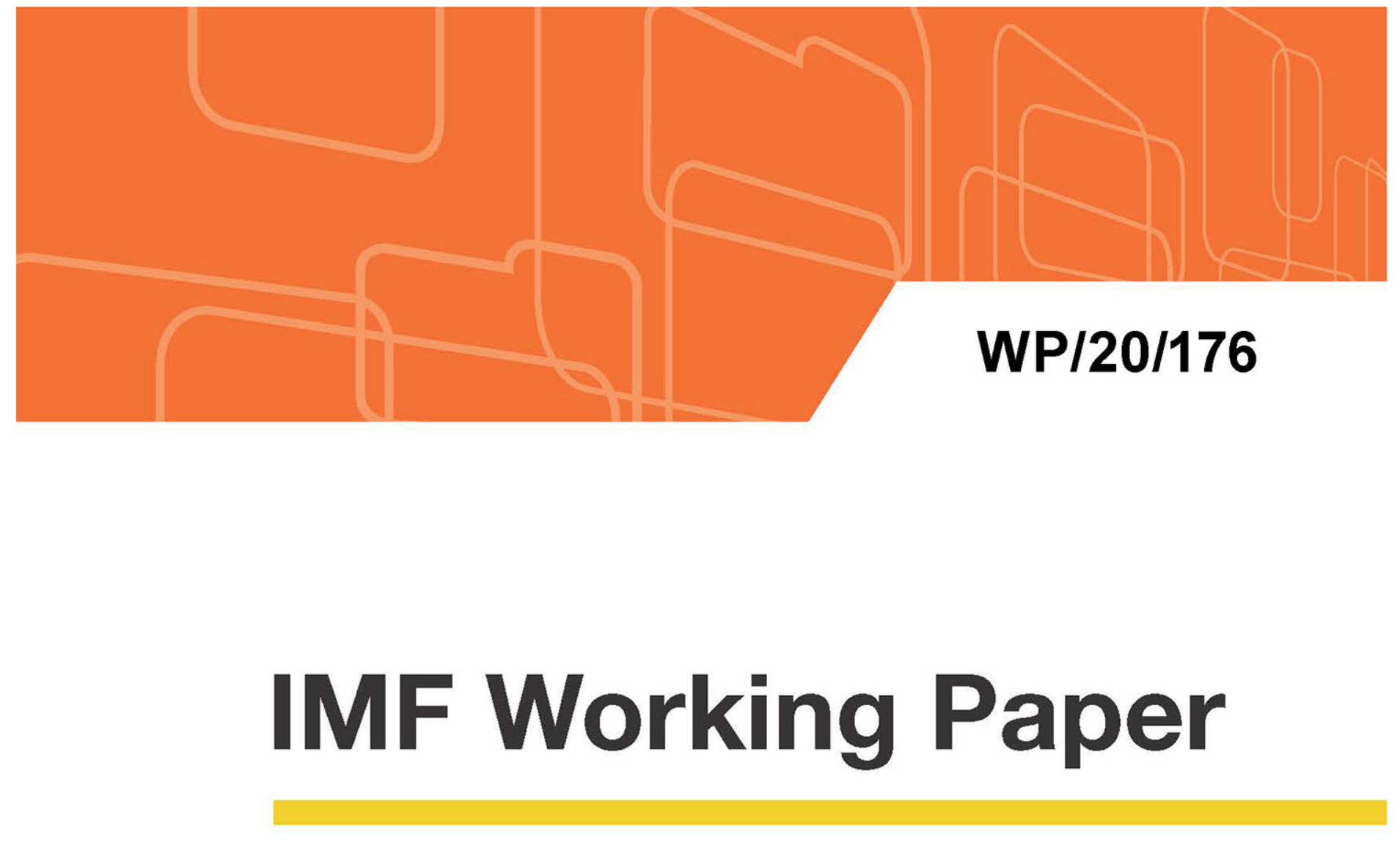

\title{
Coordinating Revenue Incentive Policies in the Caribbean
}

by Ding Ding, Samira Kalla, Manuel Rosales Torres, Abdoul Karim Sidibé

IMF Working Papers describe research in progress by the author(s) and are published to elicit comments and to encourage debate. The views expressed in IMF Working Papers are those of the author(s) and do not necessarily represent the views of the IMF, its Executive Board, or IMF management.

$$
\text { I N T E R N A T I O N A L M O N E T A R Y F U N D }
$$




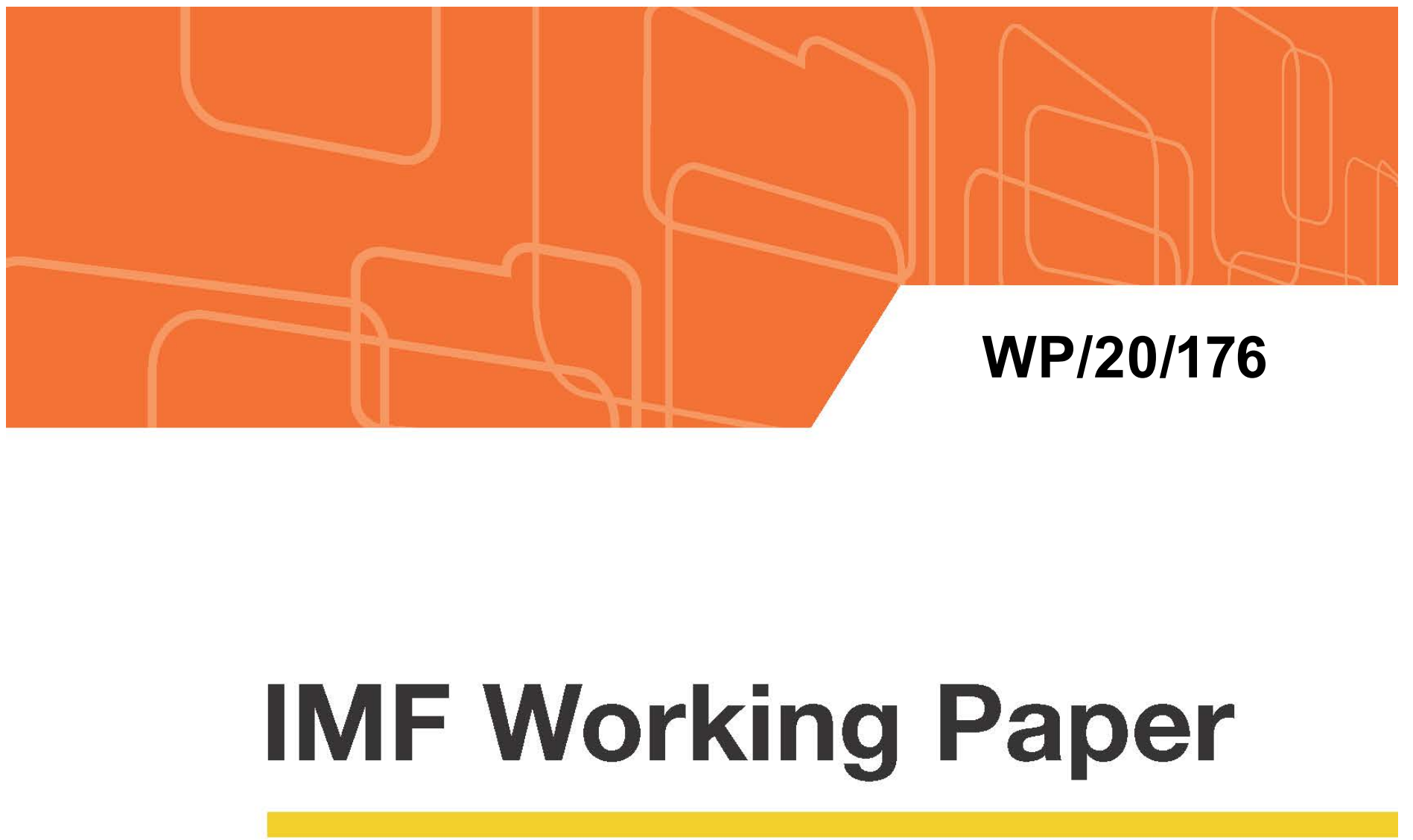

\section{Coordinating Revenue Incentive Policies in the Caribbean}

by Ding Ding, Samira Kalla, Manuel Rosales Torres, Abdoul Karim Sidibé

IMF Working Papers describe research in progress by the author(s) and are published to elicit comments and to encourage debate. The views expressed in IMF Working Papers are those of the author(s) and do not necessarily represent the views of the IMF, its Executive Board, or IMF management.

$$
\text { I N T E R N A T I O N A L M O N E T A R Y F U N D }
$$




\title{
IMF Working Paper
}

Western Hemisphere Department

\author{
Coordinating Revenue Incentive Policies in the Caribbean \\ Prepared by Ding Ding, Samira Kalla, Manuel Rosales Torres, Abdoul Karim Sidibé1 \\ Authorized for distribution by Sònia Muñoz
}

August 2020

\begin{abstract}
IMF Working Papers describe research in progress by the author(s) and are published to elicit comments and to encourage debate. The views expressed in IMF Working Papers are those of the author(s) and do not necessarily represent the views of the IMF, its Executive Board, or IMF management.
\end{abstract}

\begin{abstract}
The pervasive use of tax incentives is costly for the Caribbean countries, yet the benefits seem limited. Better policy coordination at the regional level is needed to help overcome the collective action problems and generate more revenue to support the much-needed infrastructure investment. Using the region's Citizenship-by-Investment (CBI) programs as an example, we also show that a price-quantity coordination mechanism can help achieve an efficient outcome with greater CBI incomes for member countries.

JEL Classification Numbers: E62, F69, H25, H87

Keywords: tax incentives, tax competition, tourism, foreign direct investment, citizenshipby-investment, regional policy coordination

Author's E-Mail Address: dding@,imf.org; skalla@,worldbank.org; mrosales@imf.org; abdoul.karim.sidibe@umontreal.ca

\footnotetext{
${ }^{1}$ The authors are gra teful for the comments from Ernesto Crivelli, Jeff Danforth, Alejandro Guerson, Kotaro Ishi, Vinette Keene, Alex Klemm, Bogdan Lissovolik, Sònia Muñoz, Muyangwa Muyangwa, Aza el Perez, and participants of the IMF Western Hemisphere Department(WHD) seminar, as well a s the tax and customs data provided by the Caribbean a uthorities. This document was prepared before COVID-19 became a global pandemic and resulted in unprecedented economic strains. It, therefore, does not reflect the implications of these developments and related policy priorities. We direct you to the IMF COVID-19 page that includes staff recommendations with rega rd to the outbreak. All errors of the paper are of the authors.
} 


\section{TABLE OF CONTENTS}

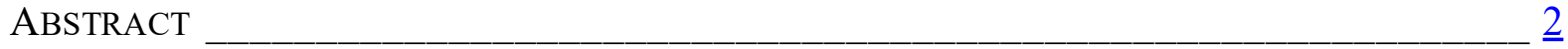

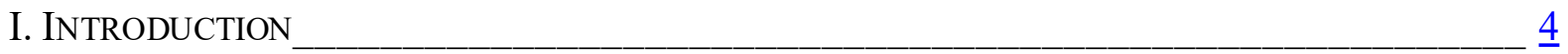

II. EstimAting THE FORGONE REVENUE FOR THE ECCU COUNTRIES ____________ $\underline{\mathbf{5}}$

III. THE IMPACT OF TAX INCENTIVES FOR TOURISM-BASED CARIBBEAN ECONOMIES______ $\underline{8}$

IV. A Price-Quantity COORdination MeChanism for the CBIS ____________

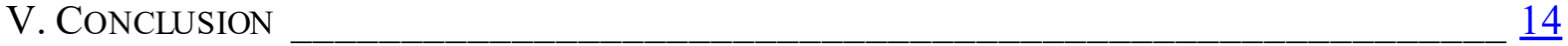

APPENDIX

A Price-QuAntity CoORdinAtion MeChanism FOR CBIS

REFERENCES 


\section{INTRODUCTION}

1. Limited fiscal space has long been an important policy challenge for the Caribbean countries. Faced with high public debt and low growth, the Caribbean countries have often struggled to raise enough revenue to finance the much-needed investment in human capital and resilience against natural disasters and climate change. While the weak revenue performance is in part due to sluggish economic growth, a narrow tax base and the pervasive use of tax incentives are also important contributing factors.

2. Tax incentives are common in the Caribbean, especially in the region's tourism sector where countries compete head to head for investments in hotel projects. ${ }^{2}$ Given the large similarity in their tourism products, countries often feel compelled to offer incentives packages out of the fear that otherwise investors will move potential investment to a competing destination in the region. The pressure to engage in a tax competition is particularly high for the region's tourism-dependent economies where tourism, directly and indirectly, contributes a lion's share of economic activities and is often the largest employer outside the public sector.

3. The pervasive use of (and competition on) tax incentives is costly for the Caribbean countries, not only creating an uneven playing field for domestic investment but also resulting in negative externalities that undermine countries' efforts to raise revenues to finance human and capital investment. On the other hand, the literature suggests that the benefits of tax incentives on growth and employment are marginal at best (Chai and Goyal 2008, Parys and James 2010, and Klemm and Parys 2012). As many Caribbean countries are faced with growing fiscal costs of natural disasters and climate change, how to enhance revenue collections without hurting competitiveness becomes a key policy challenge.

4. A similar competition also exists among the five Eastern Caribbean Currency Union (ECCU) countries that offer the citizenship-by-investment (CBIs) programs. ${ }^{3}$ The CBIs give foreign high-net-worth individuals opportunities to obtain citizenship or residency in the respective ECCU countries in exchange for financial contributions to the domestic economy. Following substantial inflows to St. Kitts and Nevis and Dominica under these programs in the early 2010s, three other ECCU countries-Antigua and Barbuda, Grenada, and St. Lucia-launched their own programs in 2013-15. The CBIs have become an important revenue source for the ECCU countries, contributing to 3.5 percent of GDP of their combined GDP in 2016. However, as the CBI programs often target the same type of overseas investors (the ECCU citizenship programs are priced in the $\$ 100,000-200,000$ range, while the economic residence programs offered by the advanced economies are at

\footnotetext{
${ }^{2}$ McIntyre (2017) provided a comprehensivereview of thetax incentive issues in the Caribbean.

${ }^{3}$ The ECCU consists of six independent countries (Antigua and Barbuda, Dominica, Grenada, St. Kitts and Nevis, St. Lucia and St. Vincent and the Grenadines) and two British Overseas Territories (Anguilla and Montserrat).
} 
much higher prices), price competition within the ECCU has intensified in recent years, raising concerns on the integrity and credibility of the CBIs as well as on fiscal sustainability of the countries that rely the most on $\mathrm{CBI}$ revenues.

5. The lack of a rules-based and transparent system for such revenue incentive policies can create governance challenges for the Caribbean countries. Governments in the region often exercise discretion in negotiating with investors and granting incentive packages on a case-by-case basis, which could leave many investors concerned about unequal treatment and favoritism. Such practices can also put countries under international scrutiny on tax avoidance with many tax jurisdictions in the region labeled by the European Union as "noncooperative tax jurisdictions and high-risk third countries." Lack of progress towards transparent tax systems increases the risks of potential sanctions that will further constrain resources available to finance economic development. ${ }^{4}$

6. In this paper we attempt to shed some lights on the benefits of coordinating revenue incentive policies in the Caribbean. We first estimate the foregone tax revenues for the ECCU countries using granular information collected from revenue and customs administrations across the region. We then conduce cross-country regressions to examine whether tax incentive policies can be associated with any material economic benefits. Our analysis points to large fiscal costs of tax incentives but only limited benefits - a result in line with the existing literature. The cross-country regression results also suggest a policy tradeoff between granting tax incentives and attracting FDI through better provision of public infrastructure, and the latter can be achieved through better coordination at the reginal level on revenue incentive policies. Given that CBIs are a unique revenue source for the ECCU countries, in section IV we design a two-country Bertrand competition model to illustrate that indeed higher revenues can be achieved by coordinating CBI policies through a combination of price and quantity instruments.

\section{ESTIMATING THE FORGONE REVENUE FOR THE ECCU COUNTRIES}

7. In this section we quantify the fiscal costs of tax incentives for the six ECCU independent countries. The analysis is based on granular information collected from tax and customs administrations across the region. It is worth noting that, recognizing the high costs of tax incentives, the ECCU member countries agreed under the 2006 Treaty of Basseterre, "to the progressive harmonization of taxation policies and incentive legislation." Against this background, tax incentives for the tourism and manufacturing sectors are supposedly governed by the Hotels Aid Act and the Fiscal Incentives Act, respectively.

\footnotetext{
${ }^{4}$ As of March 2019, the EU list of non-cooperative tax jurisdictions included 15 jurisdictions, of which 7 are from the Caribbean: Aruba, Barbados, Belize, Bermuda, Dominica, Trinidad and Tobago and the U.S. Virgin Islands.
} 
8. In practice, however, tax incentives regimes in the ECCU have become less uniform over time. This stems from the concerns that harmonizing tax incentives would reduce the country's competitiveness as a destination for tourism sector investment, especially given the countries' largely homogenous tourism products. In this context, tax competition, including through lower statutory corporate income tax (CIT) rates (by all six ECCU countries), longer tax holidays (by Antigua and Barbuda) and loss carry-forward year (by Antigua and Barbuda and Grenada), and higher investment tax allowances/tax credits (by Antigua and Barbuda and Grenada), has intensified over the years (Figure 1). Generous tax concessions are also granted at customs for import duties, VAT, and excise taxes.

\section{Figure 1. Change of Tax Policies in the ECCU Countries}

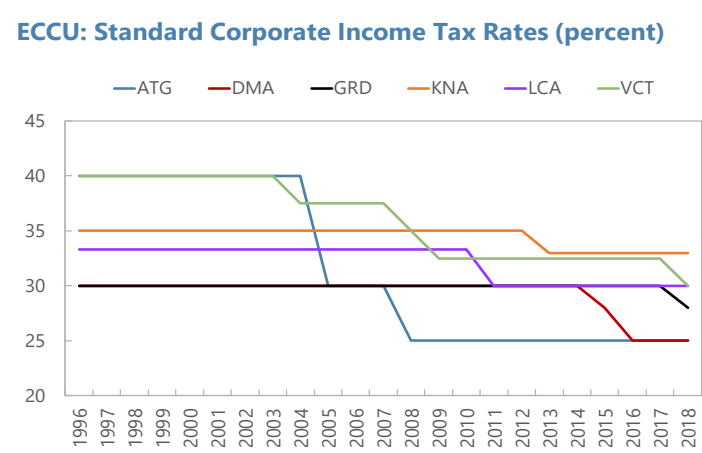

Sources: ECCU authorities; PWC Worldwide Tax Summaries; Deloitte International Tax Highlights.

ECCU: Investment Allowance/Tax Credit (in percent)

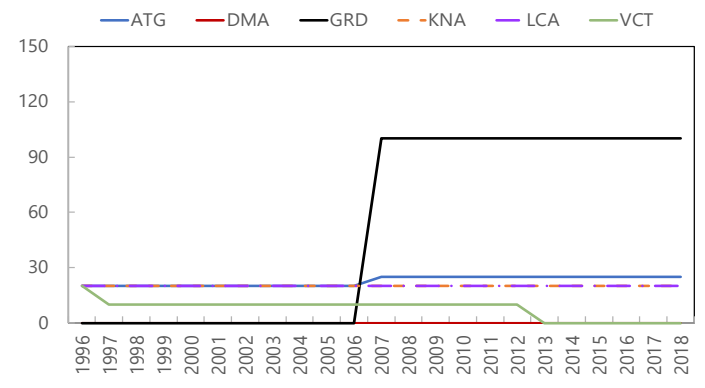

Sources: ECCU authorities; PWC Worldwide Tax Summaries; Deloitte International Tax Highlights.

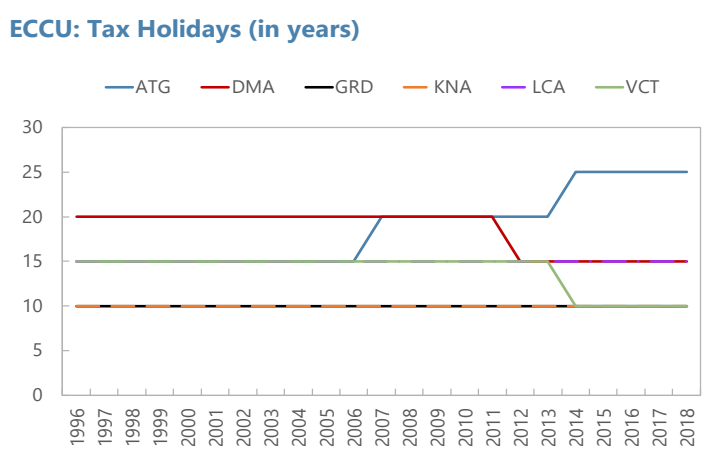

Sources: ECCU authorities; PWC Worldwide Tax Summaries; Deloitte International Tax Highlights.

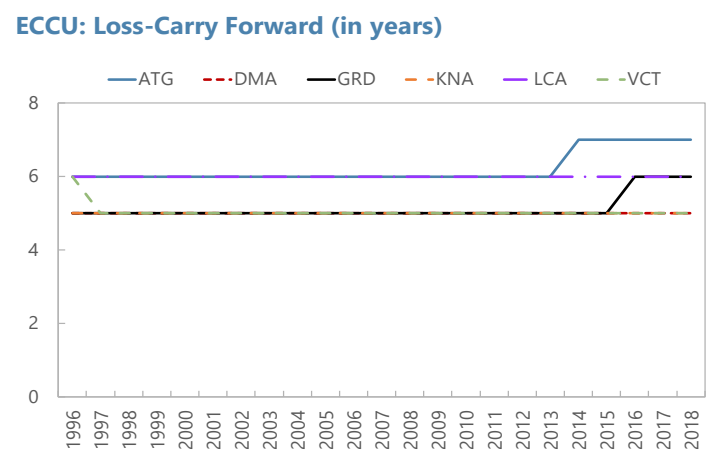

Sources: ECCU authorities; PWC Worldwide Tax Summaries; Deloitte International Tax Highlights.

9. Our measurement of tax expenditure includes the CIT foregone revenue and the cost of concessions granted at customs. The estimation of the CIT foregone revenue is based on sector-specific value-added data from national accounts, where the potential CIT base is calculated as one-fourth of the value-added for the economic sectors benefiting from tax incentives from national accounts. ${ }^{5}$ The foregone revenue at customs reflects indirect taxes and fees/charges waived by the governments when qualified beneficiaries import goods into

\footnotetext{
${ }^{5}$ The assumption of CIT base as one-fourth of the valuea dded is from Chai and Goyal(2008), which estimated the a ctual corporate profits in Jamaica at 25 percent and applied the ra tio to the ECCU countries.
} 
these economies including import duties, excise taxes, and VAT. The total foregone revenue is estimated to have averaged 5.8 percent of GDP in 2010-18 in the ECCU, or 21 percent of total tax revenue (Figure 2). These results are broadly in line with previous studies for the ECCU countries (e.g., Chai and Goyal 2008), as well as the estimation of other tourismbased Caribbean economies such as Barbados and Jamaica (IMF 2017). It is worth noting that, measured against employment, the cost of tax incentives is equivalent to as high as $\$ 2,500$ per job in the formal sector (Figure 2). ${ }^{6}$

Figure 2. The Fiscal Costs of Tax Incentives
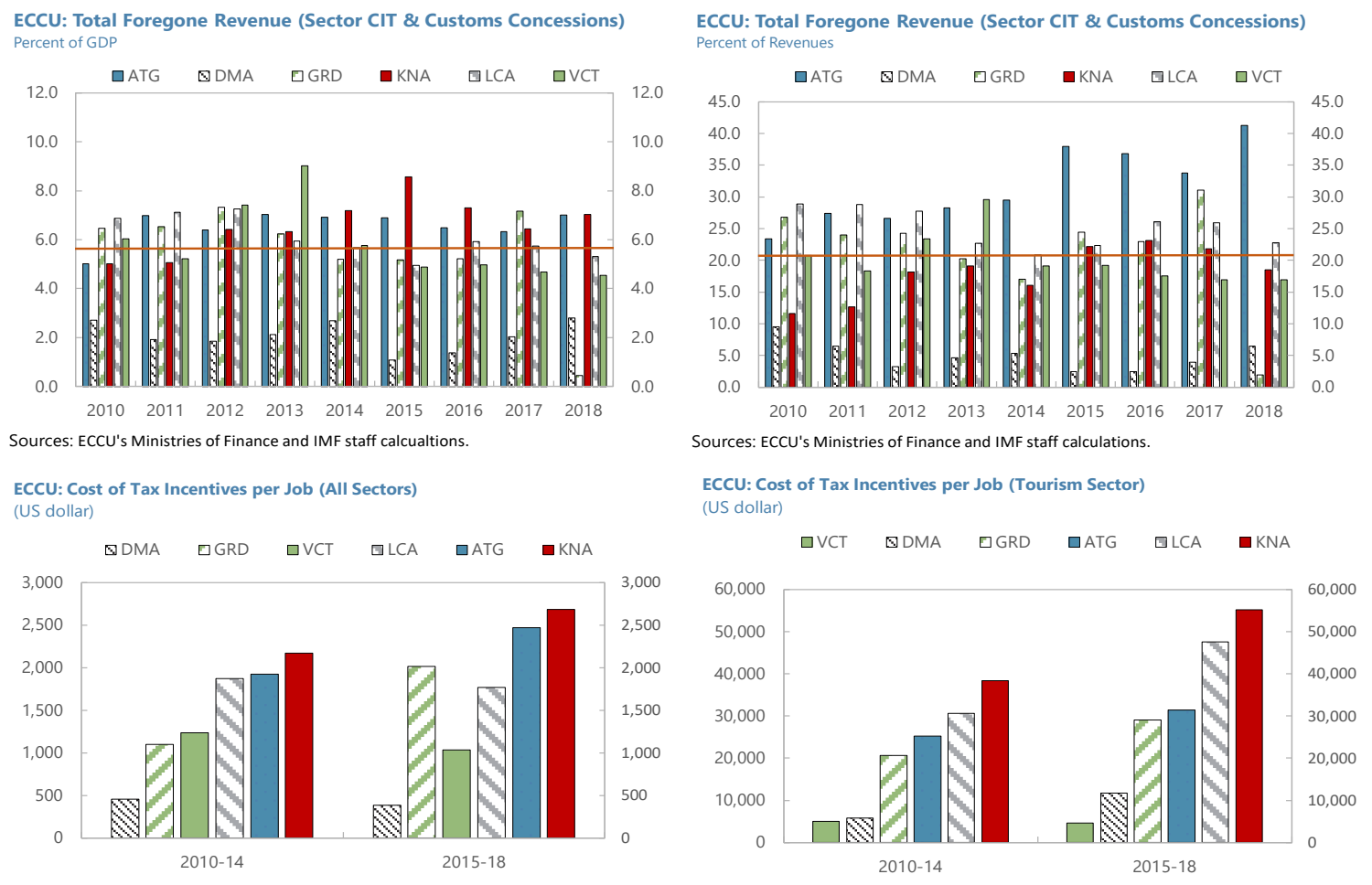

\footnotetext{
${ }^{6}$ The estimations of foregone revenues do not take into consideration the ela sticity of tax incentives with respect to GDP or employment. As shown in the next section, the use of tax incentives does not seem to have a sta tistically significant impact on investment or employment.
} 


\section{THE IMPACT OF TAX INCENTIVES FOR TOURISM-BASED CARIBBEANECONOMIES}

10. A common argument in support of the use of tax incentives is that, without such incentives, investment and job creation would not have happened. However, the literature has found little evidence to support this argument from a cross-country perspective (e.g., Chai and Goyal 2008 and Klemm and Parys 2012). In this section, we update the cross-country analysis on the economic impact of tax incentives in the Caribbean with the latest macroeconomic and tax incentive data (including forgone revenue estimations in the previous section). Because the ECCU countries compete with other tourism-based economies in the region for foreign investment, we expand the analysis to ten tourism-based Caribbean countries that include (in addition to the six independent ECCU countries) The Bahamas, Barbados, the Dominican Republic, and Jamaica. The sample period is 1996-2018.

\section{Figure 3. Tax Competition Index}

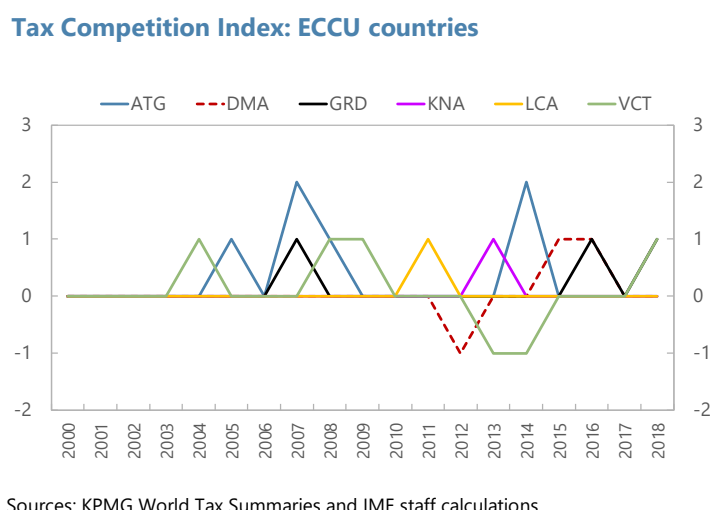

Sources: KPMG World Tax Summaries and IMF staff calculations.

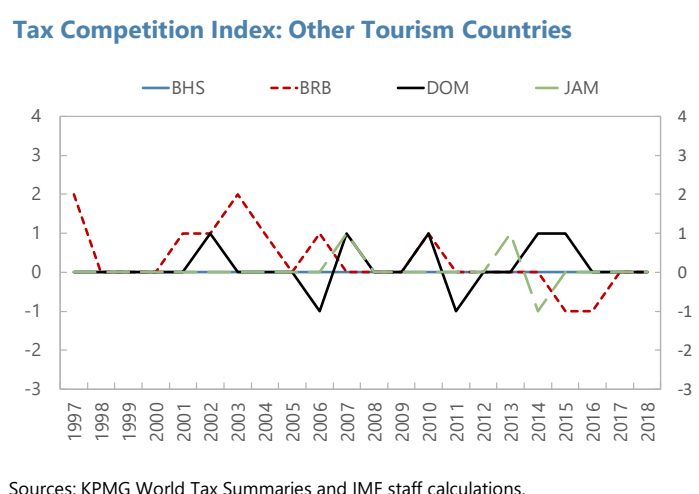

Sources: KPMG World Tax Summaries and IMF staff calculations.

11. The main variables of interest are the CIT rate as well as tax incentive measures (the length of tax holidays and the investment allowance rate). We also construct a tax competition index to measure the number of tax incentive changes on an annual basis. The index is the total number of measures taken within a calendar year to loosen tax incentives and/or lower the CIT rate (Figure 3). In order to capture the overall impact of different tax incentives, we also include the estimated foregone revenue for the ECCU countries. Other control variables include a set of domestic and external indicators in line with the literature. Public consumption, defined as the sum of compensation to employees and purchases of goods and services, serves as a proxy for the underlying fiscal policy. ${ }^{7}$ The Real Effective Exchange Rate (REER) and real US PPP GDP indicate the potential role of competitiveness and push factors, respectively. We also include the number of airlifts and the stock of infrastructure as potential factors indicating the attractiveness of the country for foreign investors. Finally, we include a dummy variable for the occurrence of natural disasters. The

\footnotetext{
${ }^{7}$ The rational of using public consumption rather than total spending is beca use public investment in many small tourism-based Caribbean economies is driven by external (including concessional) financing.
} 
macroeconomic indicators were collected from the World Bank and the IMF's World Economic Outlook (WEO) and other internal databases. The source of the data on natural disasters is The Emergency Events Database (EM-DAT).

12. We follow the specification in Klemm and Van Parys (2009). Specifically, we estimate the following dynamic panel model:

$$
F D I_{i t}=\delta F D I_{i t-1}+\operatorname{Tax}_{i t} \gamma+X_{i t} \beta+\mu_{t}+\varepsilon_{i t}
$$

where $F D I_{i t}$ is the dependent variable, $\operatorname{Tax}_{i t}$ is a vector of the tax variables described in Table $1 ; X_{i t}$ is a vector of control variables; $\mu_{t}$ are country fixed effects; and $\varepsilon_{i t}$ is independently and identically distributed error term. Subscripts $i$ and $t$ indicate the country and time period, respectively. The same specification is used to estimate the effect of tax incentives on the number of hotel rooms instead of FDI. Furthermore, to ensure a normal distribution of the data, FDI, the number of hotel rooms, infrastructure and U.S. PPP GDP underwent natural logarithmic transformation, whereas government consumption is expressed as percent of GDP to guarantee its stationarity.

13. The model is estimated using country Fixed Effect (FE) and System Generalized Methods of Moments IV (IV-GMM). We begin by estimating a dynamic FE panel model and then use System IV-GMM estimation techniques to address potential endogeneity concerns. Nevertheless, the small sample size makes FE estimations preferable and more reliable. The individual country fixed effect accounts for country heterogeneity, including factors such as the country's business environment. To avoid overfitting the regressions, we do not apply the time fixed effect. Instead, we include potential time-varying common factors, such as the occurrence of natural disasters, among the control variables. Therefore, the discussion in the following section focuses on the FE estimation results, while reporting the GMM results indicatively.

14. To the extent public consumption provides an indication about the underlying fiscal position, we expect it to be negatively associated with FDI, i.e. an increase in public consumption is ceteris paribus interpreted as a deterioration in the fiscal outlook by foreign investors. In line with the literature, REER is expected to be negatively associated with FDI as real appreciation indicates a loss in competitiveness. At the same time, an increase in real US PPP GDP would stimulate foreign investment in the region. Similarly, improved attractiveness of the region, indicated by better air access (higher number of flights) and a higher stock of infrastructure, would lead to an increase in FDI. Finally, the interaction of infrastructure and the natural disaster dummy is expected to have a positive relationship with FDI.

15. Table 1 shows the effect of a change in CIT rates and tax incentives on overall FDI. Columns $1-5$ show the baseline FE regression results, with each column using a different tax incentive indicator while the CIT rate is included in each specification. Column(5) indicates 
the IV-GMM results. Neither the change of the CIT rate or granting tax incentives is significant either statistically or economically, suggesting that they do not have a material impact on attracting FDI.

16. In terms of other control variables, public consumption is statistically significant and negatively associated with FDI across all specifications. As explained above, to the extent an increase in public consumption could lead to a worsening of the fiscal balance, this could negatively affect foreign investors' perception of risk and thus their investment decisions. While REER does not seem to be a significant driver of FDI, the coefficients of the number of flights and U.S. PPP GDP are positive and statistically significant. The stock of infrastructure is only significant when interacted with the natural disaster dummy. This is consistent with the observation that the better is the provision of public infrastructure, the more resilient is the tourism sector against natural disasters. The positive coefficient, however, indicates that raising revenue to finance infrastructure investment might be a more efficient way to attract FDI than granting tax incentives. ${ }^{8}$

17. We then estimate the model using the number of hotel rooms as a proxy for FDI in the tourism sector, given the fact that investments in the tourism-based Caribbean countries are concentrated in the tourism sector (Table 2). In contrast with the baseline results, there are mixed results regarding the role of tax incentives. For example, the CIT rate is negatively associated with the number of hotel rooms (and statistically significant when controlling for investment allowance rate). In a pooled OLS regression, we also found that an increase in the foregone revenue by 1 million EC dollars is associated with an increase in the number of hotel rooms by 0.2 percent for the ECCU countries (Table 3). Finally, we find that tax incentive measures do not seem to have an impact on overall FDI, GDP growth, or employment for the tourism-dependent Caribbean economies, in line with the literature (Table 4 and 5).

18. The limited impact of tax incentives on FDI, growth and employment suggests that there is scope for the Caribbean countries to harmonize the use of such measures without hurting the domestic economy. However, as noted in McIntyre (2017) and Al-Hassan et al (2020), the negative externalities make it difficult for countries to reduce tax incentives unilaterally. Better institutional coordination at the regional level, for instance by introducing rule-based measures and enhancing transparency, could help address the collective action problems. In the next section, we use the CBI programs as an example to illustrate how a rule-based coordination mechanism can indeed lead to an efficient (thus welfare improving) outcome for the participating countries.

\footnotetext{
${ }^{8}$ Béna ssy-Quéré et al(2007) show that there is a "high tax, high public goods" strategy to a ttract capital, in contrast to the race-to-the-bottom "low tax, low public goods"stra tegy.
} 


\section{A Price-Quantity CoORdination Mechanism for the CBIS}

19. The competition among the ECCU countries to attract foreign investment through the CBIs has intensified in recent years, exemplifying another race to the bottom in the region. ${ }^{9}$ For example, Dominica amended its CBI requirements in end-2016, lowering the fee for the real estate investment option to expand hotel construction. St. Lucia substantially eased the conditions for access by reducing the cost to generate more revenue and enhance the program's competitiveness. Antigua and Barbuda reduced the overall price nearly by half in late 2017. St. Kitts and Nevis rolled out a Hurricane Relief Fund (HRF) in early 2018, lowering the price for donations to the development fund and allowing family members to come for free, to make the program more competitive and support real estate developers.

20. A regional approach to manage the CBIs would help sustain the programs' long-term viability and their contributions to public finance. In the short term, protection of the programs' financial integrity offers an initial rationale for collective action, including to dispel concerns relating to the tax rate on offshore income and residency period and other aspects of transparency standards to lower perceptions of abuse of CBI programs. In March 2019 , the ECCU launched an initiative to harmonize CBI programs' due diligence processes. Implementation of this initiative could help the region-wide sustainability of the revenue flows and support financial stability. In the medium term, the following analysis suggests a case for exploring CBI program coordination on pricing and the use of quotas to support these revenues over time.

21. In theory, CBI competition can be thought of as a Bertrand price competition where countries use the required $\mathrm{CBI}$ investment as a strategic variable, which is perceived by foreign applicants as the price for citizenship. The conventional wisdom is that price competition leads competitors to a suboptimal outcome and policy coordination could improve their joint outcome (Deneckere and Davidson 1985). If countries are identical, then countries' revenue from CBI programs could improve either through a minimum price or (equivalently) by an appropriate cap on the number of new citizens per country. However, if countries face asymmetric demands for their CBI programs, a minimum price and a maximum quantity quota will have different effects. We show in this section that a combination of price and quantity instruments can generate the Pareto efficient outcome for member countries.

22. The intuition can be illustrated by a simple example with linear CBI demand with respect to prices. We consider $n$ countries that can be classified into two groups: the lowdemand countries $(L)$ and the high-demand countries $(H)$, depending on, for instance, the freedom of travel associated with their respective citizenships. ${ }^{10}$ Countries are assumed to be

\footnotetext{
${ }^{9}$ For the background ofCBIs, see Xu et al(2015).

${ }^{10}$ In the CBI market, the demand for ea ch country's citizenship is highly dependenton the number of countries that grant visa-free access or visa-on-arrival a ccess to the holder of the CBI country passport. Among the ECCU
}

(continued...) 
identical within each category, with the former facing less demand than the latter but with symmetric elasticities with respect to prices and producing CBI at an identical constant marginal cost. As in Deneckere and Davidson (1985), we assume that demand functions can be expressed in the following linear form

$$
q_{i}^{j}(\widetilde{p})=v_{i}-p_{i}^{j}-\delta\left(p_{i}^{j}-\bar{p}\right)
$$

where $q_{i}^{j}(\tilde{p})$ is the demand to the $j$-th $i$-type country with $i \in\{L, H\}$ and $j \in\left\{1,2, \ldots, n_{i}\right\}, \delta>$ 0 is a substitutability parameter, $\bar{p}$ is the average price level in the economy and $v_{H}>v_{L}$. We assume $v_{L}$ to be large enough so that, $q_{i}^{j}(\tilde{p})$ is always positive. In a Non-Cooperative Equilibrium, the $H$-type countries charge a higher price and grant a greater number of new citizenships than the $L$-type countries do. Therefore, while imposing a minimum price would be more biding to the $L$ s, a maximum quota limit on new citizenships would be more restrictive to the $H$ s.

23. Pareto improvement can be achieved by moving from a Non-Cooperative Equilibrium to a cooperative one. The Cooperative Equilibrium prices are determined by the intersection of the best response functions of $L$-types and $H$-types under cooperation. In Figure A1 of Appendix 1, the dashed blue (green) line represents the iso-revenue curve for $L$-types ( $H$ types) that corresponds to their Non-Cooperative Equilibrium revenue level. Any point located above the dashed blue line (to right of the dashed green line) represents a combination of prices that can generate a higher CBI revenue for the $L$-types ( $H$-types) than the one produced by the Non-Cooperative Equilibrium. Therefore, the shaded area of the graph represents the sets of prices that represent a revenue improvement for both sets of countries from the non-cooperative scenario. In Figure A1, the equilibrium prices under a minimum price and a maximum quota are higher for $L s$ and $H$ s than their respective noncooperative prices, $p_{L}^{N}$ and $p_{H}^{N}$.

24. Moreover, it can be shown that a combination of the price and quantity instruments could allow countries to reach a Pareto-efficient outcome (see Appendix I for proof). The intuition is as follow:

- Because the minimum price is always binding for the type- $L$ countries (but not always the type- $H$ countries), the marginal revenue from increasing the minimum price is always higher for the $H$-type, that is, an additional increase in the minimum price generates more revenue for the $H$-type countries than for the $L$-type countries. When the minimum price becomes high enough, its marginal benefit turns negative for the $L$-type countries but remains positive for the $H$-type countries.

countries, St. Kitts and Nevis and Antigua andBarbuda receive a higher score from the Score ofDiversity of Travel Freedom than Dominica, Grenada and St. Lucia. 
- Because the Pareto efficiency is achieved when the revenue generated in the $H$-type countries due to an additional unit to the minimum price is equal to the resulting loss of revenue for the $L$-type countries, this Pareto-efficient outcome may not dominate the non-cooperation equilibrium outcome (similarly for the maximum quota as the single requirement). Only a combination of both the minimum price and the maximum quota could ensure a "fair" distribution of the additional revenue from cooperation and, if chosen appropriately, the combination always guarantees an efficient outcome that is more profitable to both types compared to the noncooperative equilibrium. To illustrate the intuition, notice that any point that lay between the blue line and the green line in Figure A3 of Appendix 1 can be achieved by setting a combination of a minimum price and a maximum quota. The green line always passes above $\left(\hat{p}_{L}, \hat{p}_{H}\right)$ because otherwise, there would exist a maximum quota level for which type- $H$ countries would earn more revenue as compared to their revenue in a non-cooperative equilibrium while type- $L$ countries would earn less, which is impossible. Analogously, the blue line always lay below $\left(\hat{p}_{L}, \hat{p}_{H}\right)$.

- Because the set of efficient price distributions (black line on the graph) always passes through the shaded area (representing feasible Pareto improvements of the noncooperative equilibrium), it always exists an efficient distribution of prices profitable to all types that lay between the green line and the blue line. Therefore, the right combination of a minimum price and a maximum quota would guarantee an efficient outcome that is more beneficial to both types of country than the non-cooperative equilibrium.

25. The combination of price and quantity instruments has proved effective in the context of cross-country policy coordination. Several countries in the Pacific have been coordinating on revenues from selling fishing rights to foreign companies under the Party to the Nauru Agreement (PNA). The Agreement, through the so-called Vessel Day Scheme, sets limits on the number of fishing days that can be auctioned off by each member country during a calendar year, as well as a minimum benchmark fee for a fishing day. The Scheme has led to increased revenue for its parties through the licensing fees, decreased catch to ensure sustainable fishing, and leveraged the PNA to be a stronger international negotiator than the parties would be individually (Bernadett, 2014). ${ }^{11}$

\footnotetext{
${ }^{11}$ Full compliance with the VDS rules has proven difficult, in part due to the (pre)existing multilateral fishing a ccess a nd trade greements with major international pla yers such as the EU and the U.S. (Yeeting et a12018).
} 


\section{CONCLUSION}

26. Tax incentives are costly for the Caribbean countries, yet the benefits seem limited. Moreover, our cross-country analysis points to a tradeoff between offering generous incentive packages to foreign investors and attracting FDI through better provision of public infrastructure - the latter is particularly important when the economies are hit by natural disasters. As such, the Caribbean countries could be benefit from streamlining tax incentives and use the fiscal savings to finance the much-needed infrastructure investment.

27. Given the competitive nature of the regional tourism market, it is unlikely that a single country's effort will succeed because of the negative externalities of tax incentives. Regional policy integration, therefore, should be the most feasible solution to the collective action problems. As tax incentives are unlikely to be abandoned as a policy instrument, a pragmatic approach to address this challenge is to advance institutional integration in the Caribbean, such as to establish a common regime for the protection, promotion and facilitation of investments in the region by adopting common investment/business agreement (for a detailed discussion on regional institutional integration, see Al-Hassan et al 2020). This would likely require political backing and commitment to cooperating and setting up a regional institution with a clear political mandate to supervise and enforce the agreement. Structural reforms that improve the business environment are also important to strengthen the region's competitiveness in the global tourism market.

28. While feasible, a rule-based mechanism can be introduced to ensure regional policy coordination. For the ECCU countries, we show that a coordination mechanism using price and quantity instruments can help countries reach an efficient outcome and higher CBI revenues. By removing the incentives for a race-to-the-bottom, regional coordination mechanisms can also help protect the integrity of the CBIs and their long-run sustainability as an important revenue source for the ECCU countries. The ECCU authorities have taken steps towards policy coordination by harmonizing due diligence arrangements, adopting common standards and application protocols, and sharing information. With strong regional institutions put in place, a regional CBI price and quantity mechanism can be considered over the medium term as the next step of the regional coordination, with a goal to maximize the economic benefits of these programs. 
Table 1: The Effect of Tax Incentives on FDI (Panel Regression)

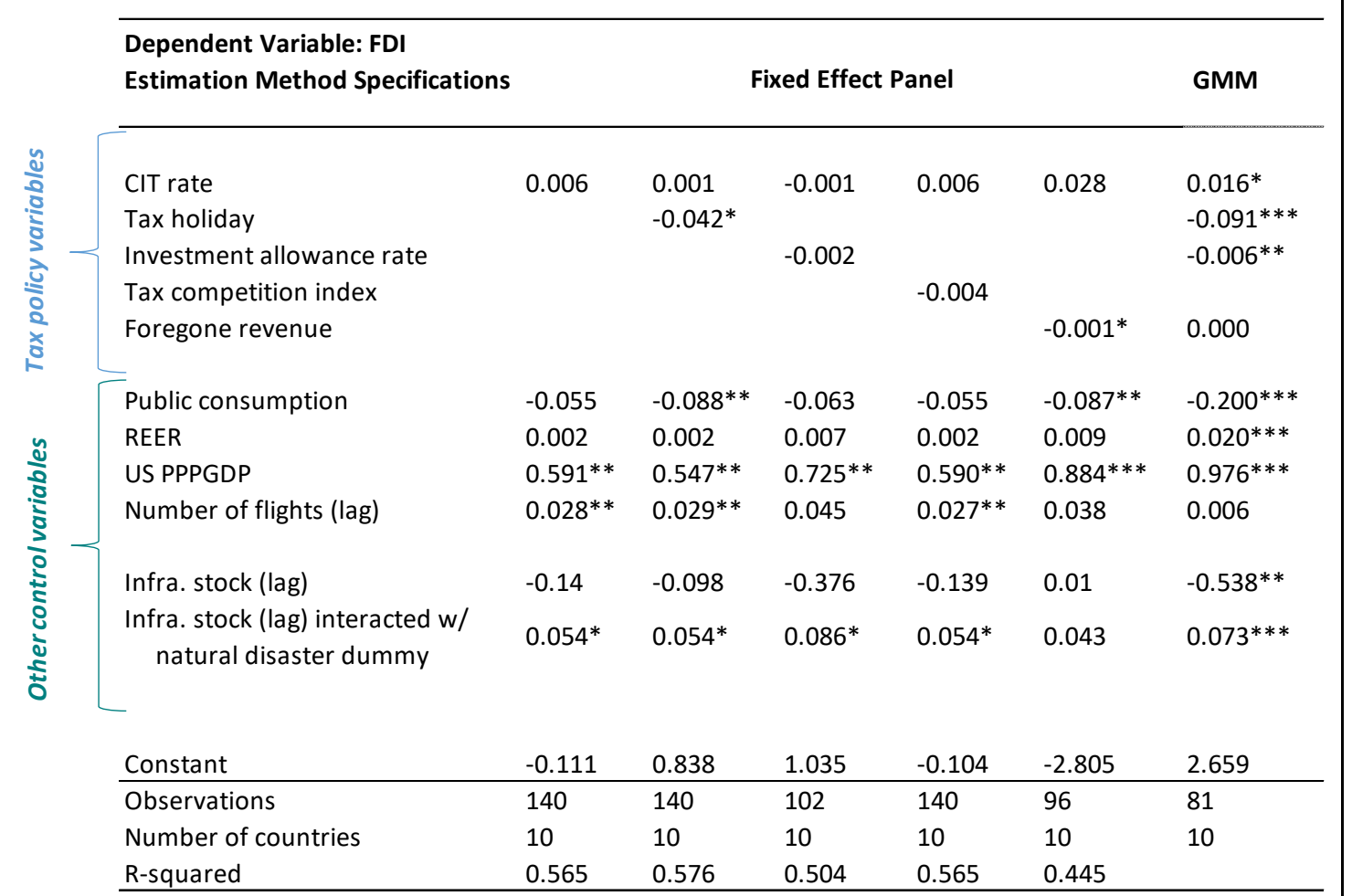

Note: the tax competition index measures the number of tax incentive changes within a year Source: IMF staff calculations 
Table 2: The Effect of Tax Incentives on the Number of Hotel Rooms (Panel Regression)

\begin{tabular}{|c|c|c|c|c|c|c|}
\hline \multicolumn{7}{|c|}{ Dependent Variable: The Number of Hotel Rooms } \\
\hline \multicolumn{3}{|c|}{ Estimation Method Specifications } & \multicolumn{3}{|c|}{ Fixed Effect Panel } & \multirow{2}{*}{$\begin{array}{c}\text { GMM } \\
0.006\end{array}$} \\
\hline CIT rate (lag) & -0.006 & -0.006 & $-0.013 * *$ & -0.006 & -0.009 & \\
\hline Tax holiday (lag) & & -0.004 & & & & $-0.074 * * *$ \\
\hline Investment allowance rate (lag) & & & $-0.003^{*}$ & & & -0.002 \\
\hline Tax competition index (lag) & & & & 0.027 & & \\
\hline Foregone revenue (lag) & & & & & 0.000 & $0.001 * *$ \\
\hline Public consumption & 0.006 & 0.004 & $0.018^{*}$ & 0.006 & 0.010 & $-0.072 * * *$ \\
\hline REER & 0 & 0 & -0.002 & 0 & 0.001 & -0.001 \\
\hline US PPPGDP & $0.129 * *$ & $0.129 * *$ & $0.197 * * *$ & $0.131^{* *}$ & $0.258 * * *$ & $0.387^{* *}$ \\
\hline Number of flights (lag) & 0.003 & 0.003 & -0.005 & 0.003 & -0.011 & -0.070 \\
\hline Infra. stock (lag 2) & $0.113^{* * *}$ & $0.116^{* * *}$ & $0.110 * *$ & $0.110^{* * *}$ & 0.073 & $-0.214^{*}$ \\
\hline $\begin{array}{l}\text { Infra. stock (lag } 2 \text { ) interacted w/ } \\
\text { natural disaster dummy }\end{array}$ & -0.012 & -0.012 & $-0.027 *$ & -0.013 & -0.017 & 0.000 \\
\hline Constant & $6.733 * * *$ & $6.813^{* * *}$ & $6.542 * * *$ & $6.695 * * *$ & $5.693 * * *$ & 4.015 \\
\hline Observations & 135 & 135 & 101 & 135 & 93 & 80 \\
\hline Number of countries & 10 & 10 & 10 & 10 & 10 & 10 \\
\hline R-squared & 0.54 & 0.317 & 0.319 & 0.468 & 0.327 & \\
\hline
\end{tabular}

Note: the tax competition index measures the number of tax incentive changes within a year Source: IMF staff calculations 


\section{Table 3: The Effect of Tax Incentives on the Number of Hotel Rooms (OLS Regression)}

Dependent Variable: The Number of Hotel Rooms Estimation Method Specification

\section{OLS}

\begin{tabular}{|c|c|c|c|c|c|}
\hline CIT rate (lag) & $-0.017 * * *$ & 0.000 & $0.027^{* * *}$ & 0.001 & $0.031 * *$ \\
\hline Tax holiday (lag) & & 0.007 & & & \\
\hline Investment allowance rate (lag) & & & 0.002 & & \\
\hline Tax competition index (lag) & & & & $0.170 * *$ & \\
\hline Foregone revenue (lag) & & & & & $0.002 * * *$ \\
\hline Public consumption & $-0.064 * * *$ & $-0.124 * * *$ & $-0.173 * * *$ & $-0.124 * * *$ & $-0.134 * * *$ \\
\hline REER & 0.001 & 0.008 & 0.01 & $0.011 *$ & 0.015 \\
\hline US PPPGDP & $-0.181^{*}$ & -0.062 & -0.065 & -0.049 & 0.276 \\
\hline Number of flights (lag) & $0.033 * * *$ & $0.041^{* * *}$ & $0.050 * * *$ & $0.041 * * *$ & $0.085 * * *$ \\
\hline Infra. stock (lag 2) & $0.275^{* * *}$ & $0.189 * * *$ & $0.115^{* * *}$ & $0.181 * * *$ & -0.16 \\
\hline $\begin{array}{l}\text { Infra. stock (lag } 2 \text { ) interacted w/ } \\
\text { natural disaster dummy }\end{array}$ & -0.02 & -0.041 & 0.074 & -0.046 & 0.016 \\
\hline Constant & $8.068 * * *$ & $7.599 * * *$ & $7.831^{* * *}$ & $7.359 * * *$ & $6.510 * * *$ \\
\hline Observations & 135 & 135 & 101 & 135 & 93 \\
\hline Number of countries & 10 & 10 & 10 & 10 & 6 \\
\hline R-squared & 0.882 & 0.894 & 0.843 & 0.899 & 0.639 \\
\hline
\end{tabular}

Note: the tax competition index measures the number of tax incentive changes within a year Source: IMF staff calculations 


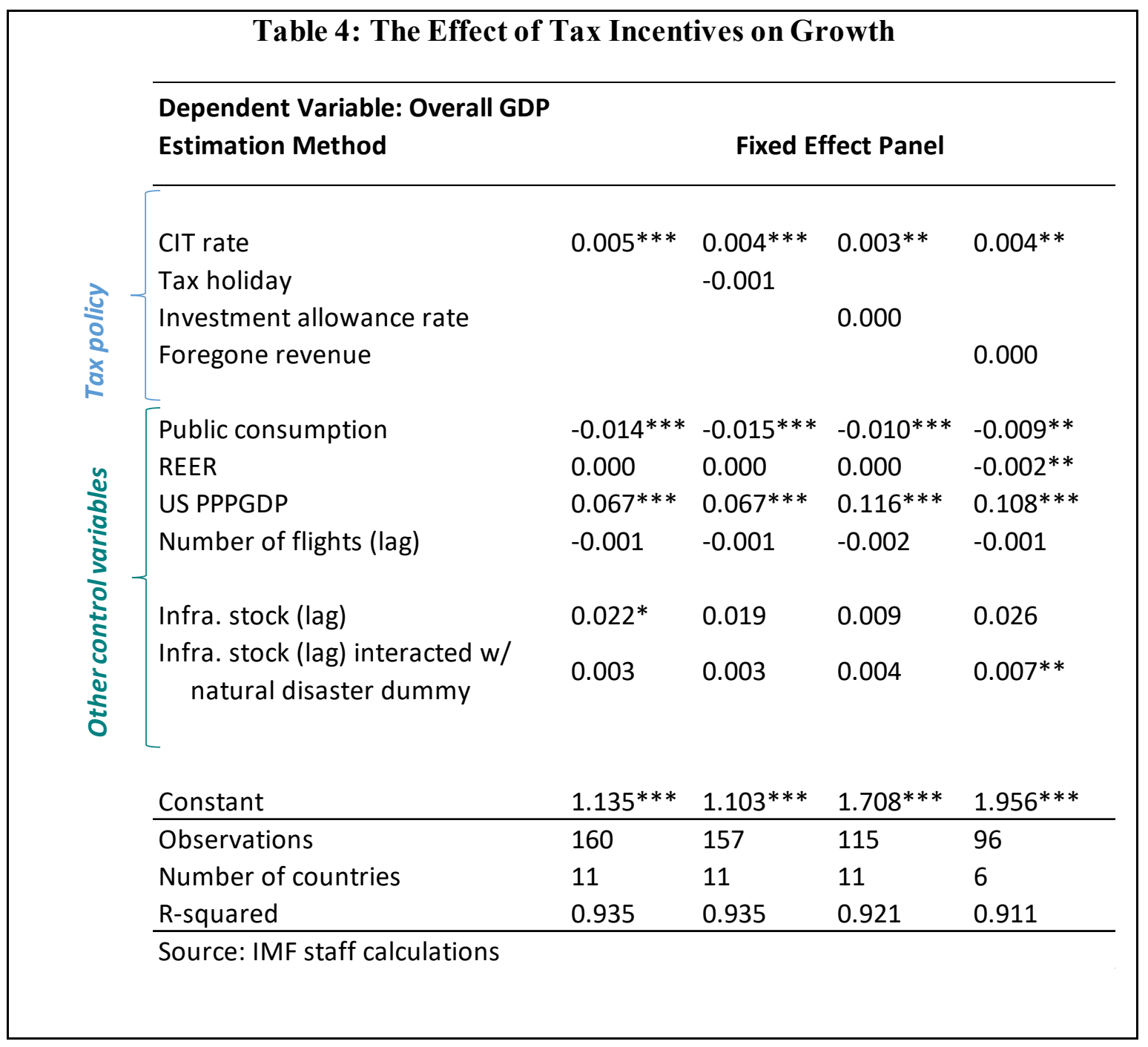

CInternational Monetary Fund. Not for Redistribution 


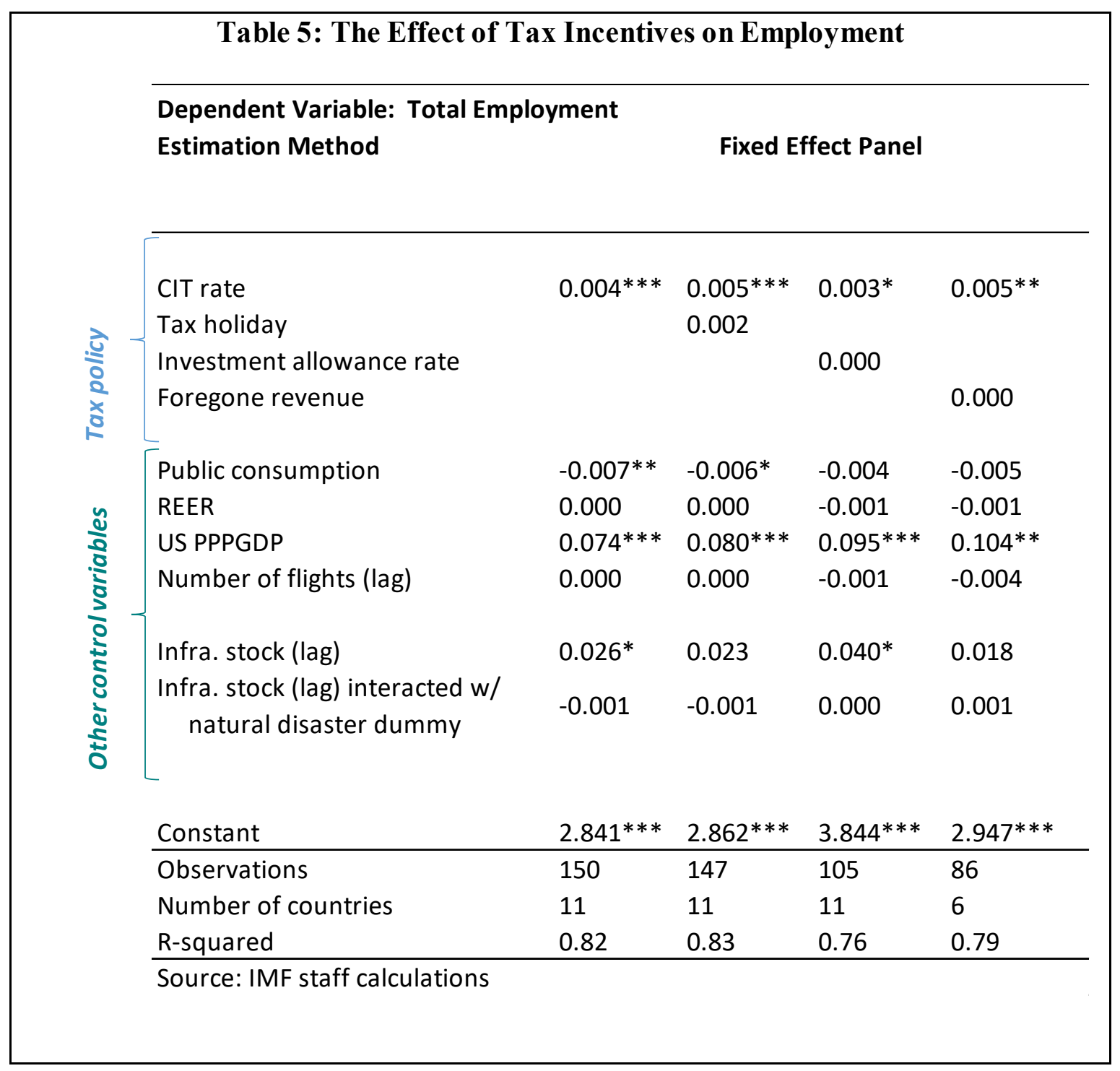

CInternational Monetary Fund. Not for Redistribution 


\section{APPENDiX. A Price-QuANTITy COORdinAtion MeChanism For CBIS}

There exists $n \geq 2$ independent countries (or states) in the economy. Each country sets a price for its CBI and faces a demand for the product that depends negatively on its own price and positively on those of others. ${ }^{12}$ Countries can be classified into two types, $L$ or $H$ according to the size of the demand they are facing. $L$-type countries facea lower demand than $H$-type countries do. For each $i \in\{L, H\}$, let $n_{i} \geq 1$ be the number of $i$-type countries, so that, $n_{L}+n_{H}=n$. A price distribution is an $\mathrm{n}$-dimensional vector $\tilde{p}=$ $\left(p_{L}^{1}, p_{L}^{2}, \ldots p_{L}^{n_{L}}, p_{H}^{1}, p_{H}^{2}, \ldots p_{H}^{n_{H}}\right) \in \mathbb{R}_{+}^{n}$ where $p_{i}^{j}$ is the price charged by the $j$-th $i$-type country (assuming that $i$-type countries are numbered from 1 to $n_{i}$ ) with $i \in\{L, H\}$ and $j \in$ $\left\{1,2, \ldots, n_{i}\right\}$. For all $\tilde{p} \in \mathbb{R}_{+}^{n}$, let $q_{i}^{j}(\tilde{p})$ be the demand to the $j$-th $i$-type country, that is, the number of applicants for CBI in that country. As in Deneckere and Davidson (1985), we assume that demand functions can be expressed in the following linear form ${ }^{13}$

$$
q_{i}^{j}(\tilde{p})=v_{i}-p_{i}^{j}-\delta\left(p_{i}^{j}-\bar{p}\right)
$$

where $\delta>0$ is a substitutability parameter, $\bar{p}$ is the average price level in the economy $\left(\bar{p}=\left(p_{L}^{1}+p_{L}^{2}+\cdots+p_{L}^{n_{L}}+p_{H}^{1}+p_{H}^{2}+\cdots+p_{H}^{n_{H}}\right) / n\right)$ and $v_{H}>v_{L}$. We assume $v_{L}$ to be high enough, so that, $q_{i}^{J}(\tilde{p})$ is always positive.

Note that the entire distribution of prices is not necessary for the determination of the demand in any given country. Only the country's own price $p_{j}^{i}$ and the average price $\bar{p}$ matter. This feature of the demand function is not crucial for our main results but helps to find closed-form solutions. If $\delta$ approaches 0 then CBIs are strategically independent. The larger is $\delta$ the more homogenous are the CBIs.

We assume that the total cost for providing citizenships is a constant $C$ and the marginal cost is zero (we can find same results with constant marginal cost). Each type $i \in\{L, H\}$ country aims to set a price level as to maximize its revenue from $\mathrm{CBI}$ defined by

$$
R_{i}^{j}(\tilde{p})=p_{i}^{j} q_{i}^{j}(\tilde{p})-C
$$

Definition 1. A price distribution $\tilde{p} \in \mathbb{R}_{+}^{n}$ is Pareto efficient if there exists no price distribution $\tilde{p}^{\prime} \in \mathbb{R}_{+}^{n}$ such that for all $i \in\{L, H\}$ and all $j$-th $i$-type country

$$
R_{i}^{j}(\tilde{p}) \leq R_{i}^{j}\left(\tilde{p}^{\prime}\right)
$$

with at least one strict inequality.

\footnotetext{
${ }^{12}$ The demand side of the market is not described explicitly, a s we will focus on the benefit from coalition from the point of view of suppliers.

${ }^{13}$ We use linear demand functions for their tractability. Martin (2009) and Fanti and Gori(2011) provide sound micro-foundations for linear Marshallian demand.
} 
It is worth noting that this definition of Pareto efficiency concerns only agents on the supply side of the market (countries) and not the well-being of agents on the demand side, which are not explicitly described in the model. Countries are supposed to compete with prices, that is, they use prices as strategic variables and try to maximize their respective payoffs in a single period game. Countries, therefore, engage in a Bertrand competition with differentiated products. It is also worth noticing that this is a supermodular game, meaning that a country's best response to an increase in prices in other countries is to increase its own price since the second cross derivatives $\partial^{2} R_{i}^{j} / \partial p_{i}^{j} \partial p_{i^{\prime}}^{j^{\prime}}=\delta / n>0$ with $\{i, j\} \neq\left\{i^{\prime}, j^{\prime}\right\}$.

In what follows, we define two types of equilibrium: the Non-Cooperative Nash Equilibrium and the Cooperative Nash Equilibrium. For notational ease, assume that all countries (both types included) are numbered from 1 to $n$. For all price distribution $\tilde{p} \in$ $\mathbb{R}^{n}$, all country $k \in\{1,2, \ldots, k\}$, and all price level $p \in \mathbb{R}$, define $\left(p, p_{-k}\right)$ by the $n$ dimensional vector obtained by replacing the $k$-th component of $\tilde{p}$ by $p$ without changing the order of the remaining components.

Definition 2. A Non-Cooperative Nash Equilibrium is a price distribution $\tilde{p}^{N}=$ $\left(p_{1}^{N}, p_{2}^{N}, \ldots, p_{n}^{N}\right)$ such that for all country $k \in\{1,2, \ldots, n\}$, if $k$ is the $j-t h i$ type country then

$$
p_{k}^{N} \in \operatorname{argmax}_{p_{k} \in \mathbb{R}} R_{i}^{j}\left(p_{k}, p_{-k}^{N}\right)
$$

Non-Cooperative Nash Equilibria are price distributions that correspond to situations where no country could increase its revenue through a unilateral deviation. If $\tilde{p}^{N}$ is a Non-Cooperative Nash equilibrium, then the first-order condition for (1) is

$$
v_{i}-2 p_{k}^{N}-\delta\left(2 p_{k}^{N}-\bar{p}^{N}-\frac{p_{k}^{N}}{n}\right)=0
$$

which implies that

$$
p_{k}^{N}=\frac{v_{i}+\delta \bar{p}^{N}}{2+\delta\left(2-\frac{1}{n}\right)}
$$

So, in a Non-Cooperative Nash Equilibrium, countries of the same type charge the same price. Denote by $p_{L}^{N}$ and $p_{H}^{N}$ the equilibrium price charged by the $L$-types and the $H$-types respectively:

$$
p_{L}^{N}=\frac{v_{L}+\delta \bar{p}^{N}}{2+\delta\left(2-\frac{1}{n}\right)}, \quad p_{H}^{N}=\frac{v_{H}+\delta \bar{p}^{N}}{2+\delta\left(2-\frac{1}{n}\right)}
$$


Equation (2) implicitly defines $p_{L}^{N}$ and $p_{H}^{N}$ as functions of the average price level given by

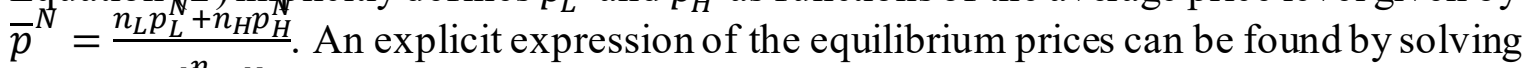
(2) for $\left(p_{L}^{N}, p_{H}^{N}\right)$ after substituting the expression of the average price into the equation. Then we get

$$
p_{L}^{N}=\frac{\delta n_{H} p_{H}^{N}+n v_{L}}{-\delta+2 n+2 \delta n-\delta n_{L}}, p_{H}^{N}=\frac{\delta n_{L} p_{L}^{N}+n v_{H}}{-\delta+2 n+2 \delta n-\delta n_{H}}
$$

Equation (3) uniquely defines the Non-Cooperative Nash Equilibrium price levels by

$$
\left\{\begin{array}{l}
p_{L}^{N}=\frac{n\left(\delta n_{H} v_{H}+2 n v_{L}-\delta\left(1-2 n+n_{H}\right) v_{L}\right)}{(-\delta+2(1+\delta) n)(2 n+\delta(-1+n))} \\
p_{H}^{N}=\frac{n\left(\delta n_{L} v_{L}+2 n v_{H}-\delta\left(1-2 n+n_{L}\right) v_{H}\right)}{(-\delta+2(1+\delta) n)(2 n+\delta(-1+n))}
\end{array}\right.
$$

We can easily verify that

$$
p_{H}^{N}>p_{L}^{N} \text { and } q_{H}^{N}>q_{L}^{N}
$$

where $q_{i}^{N}$ denotes the Non-Cooperative Nash Equilibrium quantity for $i$-type countries. In other words, in a Non-Cooperative Equilibrium, high-demand countries charge a higher price and grant a greater number of new citizenships than low-demand countries do. We know that the unique Non-Cooperative Nash Equilibrium is Pareto inefficient ${ }^{14}$. Now, suppose that countries can cooperate in order to increase their individual revenue. Assume that they can commit on a uniform lower bound for prices (minimum price) $p_{\min }$ and a uniform upper limit (maximum quota) $q_{\max }$ for the number of new applicants (quantities), that is, countries are no longer allowed to set their price below $p_{\min }$ or to provide citizenships to more than $q_{\max }$ applicants.

Definition 3. A Cooperative Nash Equilibrium is a price distribution $\tilde{p}^{C}=\left(p_{1}^{C}, p_{2}^{C}, \ldots, p_{n}^{C}\right)$ such that for all $k \in\{1,2, \ldots, n\}$ if $k$ is the $j$-th $i$-type country, then

$$
p_{k}^{C}=\operatorname{argmax}_{p_{k}} R_{i}^{j}\left(p_{k}, p_{-k}^{C}\right) \quad \text { s.t. } \quad p_{k} \geq p_{\min }, q_{i}^{j}\left(p_{k}, p_{-k}^{C}\right) \leq q_{\max }
$$

In other words, in a Cooperative Nash Equilibrium each country plays its best response to the strategies of others under the minimum price and the maximum quota constraints. While the best response of an individual country to the strategy of all the others is easily defined, the definition of the best response of one type of countries, say $i$, to the strategies of the other type, say $-i$, deserves some special considerations. Denote by $\tilde{P}\left(p_{-i}\right)$ a price distribution where $p_{-i}$ is the average price charged by the $-i$-type

\footnotetext{
${ }^{14}$ See, for instance, Friedman (1983).
} 
countries and for all country $k$, if $k$ is the $j$-th $i$-type country, then the price charged by $k$, say $P_{k}\left(p_{-i}\right)$, satisfy

$$
P_{k}\left(p_{-i}\right)=\underset{p_{k}}{\operatorname{argmax}} R_{i}^{j}\left(p_{k}, P_{-j}\left(p_{-i}\right)\right) \text { s.t. } p_{k} \geq p_{\min }, q_{i}^{j}\left(p_{k}, P_{-k}\left(p_{-i}\right)\right) \leq q_{\max }
$$

Equation (5) defines the price distribution $\tilde{P}\left(p_{-i}\right)$ such that each $i$-type country plays its best response to the strategies of all the other countries. As in Equation (2), the unconstrained solution of (5) would be

$$
P_{i}^{0}\left(p_{-i}\right) \equiv \frac{n v_{i}+\delta p_{-i} n_{-i}}{2 n+\delta\left[n+n_{-i}-1\right]}
$$

for every $i$-type country. However, since $q_{i}^{j}\left(p_{k}, P_{-k}\left(p_{-i}\right)\right)$ is a decreasing function of $P_{k}$, the maximum quota constraint also requires $P_{k}$ to be greater than some price level, say $P_{i}^{\text {quota }}\left(p_{-i}\right)$ with

$$
q_{i}^{j}\left(P_{i}^{q u o t a}\left(p_{-i}\right), P_{-k}\left(p_{-i}\right)\right)=q_{\max }
$$

Therefore, since $R_{i}^{j}\left(p_{k}, P_{-k}\left(p_{-i}\right)\right)$ is concave in $P_{k}$,

$$
\left.P_{k}\left(p_{-i}\right)=\max \left\{p_{\min }, P_{i}^{0}\left(p_{-i}\right), P_{i}^{q u o t a}\left(p_{-i}\right)\right\}\right)
$$

Note that $P_{k}\left(p_{-i}\right)$ is independent of $k$. Countries of the same type $i$ in dependently charge the same price as a response to an average price level $p_{-i}$ set by the other type. For convenience, we can replace the $k$ index by $i$ in the notation of the best response of $i$ type $P_{k}\left(p_{-i}\right)=P_{i}\left(p_{-i}\right)$.

After some algebra, $P_{i}^{q u o t a}\left(p_{-i}\right)$ can be explicitly defined by:

$$
P_{i}^{\text {quota }}\left(p_{-i}\right)=\frac{n\left(v_{i}-q_{\max }\right)+\delta p_{-i} n_{-i}}{n+\delta n_{-i}}
$$

$P_{i}^{q u o t a}\left(p_{-i}\right)$ increases with $v_{i}$ meaning that $H$-type countries are «more likely» to be affected by the quota limit and «less likely» to have a binding minimum price constraint while the $L$-types are more likely to have their best response distorted by the minimum price. A Cooperative Nash Equilibrium is entirely defined by a couple of price levels $\left(p_{L}^{C}, p_{H}^{C}\right)$ such that 15

$$
P_{L}\left(p_{H}^{C}\right)=p_{L}^{C} \text { and } P_{H}\left(p_{L}^{C}\right)=p_{H}^{C}
$$

${ }^{15}\left(p_{L}^{C}, p_{H}^{C}\right)$ depend on parameters $\mathrm{p}_{\min }$ and $\mathrm{q}_{\max }$, which are omitted for notationalea se whenever there is no risk of confusion 
Therefore, $p_{L}^{C}$ is the equilibrium price of the $L$-type countries if and only if $P_{L}\left(P_{H}\left(p_{L}^{C}\right)\right)=$ $p_{L}^{C}$. Thus, the search for Cooperative Nash Equilibria boils down to finding the fixed points of the composed function $P_{L}\left(P_{H}(\cdot)\right)$.

Proposition 1. For every minimum price $P_{\min }>0$ and maximum quota $q_{\max }>0$ there exists a unique Cooperative Nash Equilibrium.

Proof. Consider an auxiliary function $F$ defined on $\mathbb{R}_{+}$by $F(p)=P_{L}\left(P_{H}(p)\right)-p$. Now, we need to search for the zeros of $F$.

First, note that $F$ is continuous on $\mathbb{R}_{+}$and differentiable almost everywhere. $F$ is a decreasing function because for every $p$ where $F$ is differentiable, we have

$$
\begin{gathered}
F^{\prime}(p) \quad=P_{H}^{\prime}(p) \times P_{L}^{\prime}\left(P_{H}(p)\right)-1 \\
\leq \max \left\{P_{H}^{\prime}(p)\right\} \times \max \left\{P_{L}^{\prime}(p)\right\}-1 \\
\leq \frac{\delta n_{L}}{n+\delta n_{L}} \times \frac{\delta n_{H}}{n+\delta n_{H}}-1<0 .
\end{gathered}
$$

Second, since $P_{i}(p)>p_{\text {min }}, \forall p>0, i \in\{L, H\}$, we get

$$
F(0) \geq p_{\min }>0
$$

Furthermore, for high enough values of $p, P_{i}(p)=P_{i}^{q u o t a}(p)$ because $P_{i}^{q u o t a}$ increases at a higher rate than $P_{i}^{0}$ and both of then are linear. So

$$
\begin{array}{cc}
\lim _{p \rightarrow+\infty} & =\lim _{p \rightarrow+\infty} F(p) \\
= & \lim _{p \rightarrow+\infty} P_{L}\left(P_{H}(p)\right)-p \\
= & \lim _{p \rightarrow+\infty}\left(\frac{P_{L}\left(P_{H}(p)\right)}{p}-1\right) p \\
= & \lim _{p \rightarrow+\infty}\left(\frac{\delta n_{L}}{n+\delta n_{L}} \times \frac{\delta n_{H}}{n+\delta n_{H}}-1\right) p \\
=-\infty &
\end{array}
$$

From (8), (9), (10) and according to the intermediate value theorem there exists a unique price level $p_{L}^{C}>0$ such that, $F\left(p_{L}^{C}\right)=0$. So, for any given $p_{\min }$ and $q_{\max }$, there is a unique Cooperative Nash Equilibrium $\left(p_{L}^{C}, p_{H}^{C}\right)$ where $p_{H}^{C} \equiv P_{H}\left(p_{L}^{C}\right)$.

In particular, the Non-Cooperative Nash Equilibrium $\left(p_{L}^{N}, p_{H}^{N}\right)$ can be reached by any Cooperative Nash Equilibrium where the minimum price is smaller that $p_{L}^{N}$ and that maximum quota is bigger than $q_{H}^{N}$. Figure A1 shows how a Pareto improvement of a NonCooperative Nash Equilibrium through a cooperative one. Indeed, the Cooperative Nash Equilibrium prices are determined by the intersection of the best response functions of $L$ types and $H$-types under cooperation. The dashed blue (resp. green) line represents the isorevenue curve for $L$-types (resp. $H$-types) that corresponds to their Non-Cooperative Nash Equilibrium revenue level. Any point located above the dashed blue line (resp. to right of the 
dashed green line) represents a combination of prices, which will generate a higher revenue from CBI for the $L$-types (resp. $H$-types) than the one produced by the Non-Cooperative Nash Equilibrium. Therefore, the purple area of the graph represents the sets of prices distribution that generate more revenue to both countries as compared to the non-cooperative scenario.

\section{Figure A 1: A Pareto Improvement of the Non-Cooperative Nash Equilibrium through a Cooperative One}

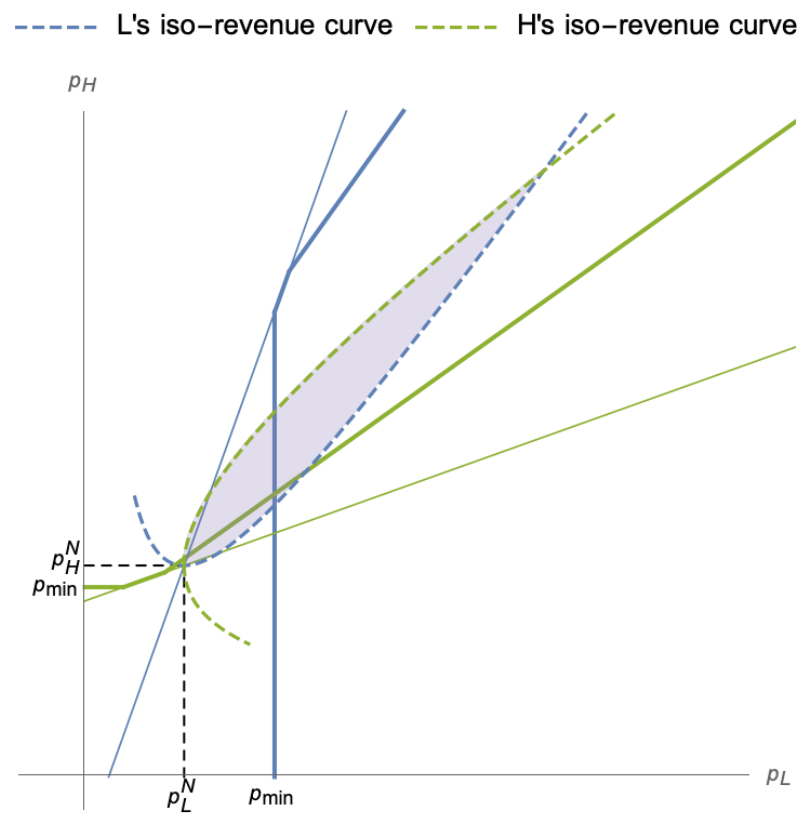

— L's Best Response under cooperation — H's Best Response under cooperation

— L's non-cooperative Best Response — H's non-cooperative Best Response

Next, we study how Pareto efficient price distributions can be achieved by a Cooperative Nash Equilibrium. First note that, Pareto efficiency does not require that countries of the same type charge the same price. However, since Cooperative Nash Equilibrium requires prices to be identical for same type countries we will consider only Pareto efficient price distributions that have this feature. Price distributions for which same type countries charge same prices are entirely defined by a couple $\left(p_{L}, p_{H}\right) \in \mathbb{R}^{2}$ where $p_{i}$ is charged by the $i$-type countries. For all $i \in\{L, H\}$, define by $q_{i}$ and $R_{i}$ the two-variable functions naturally induced, respectively by $q_{i}^{j}$ and $R_{i}^{j}$ when the price distribution is $\left(p_{L}, p_{H}\right)$.

Pareto efficient price distributions under which the same prices are charged by same type countries are all the couples $\left(p_{L}^{E}, p_{H}^{E}\right)$ characterized by:

$$
\left(p_{L}^{E}, p_{H}^{E}\right)=\underset{p_{L}, p_{H}}{\operatorname{argmax}} R_{H}\left(p_{L}, p_{H}\right) \text { s.t. } R_{L}\left(p_{L}, p_{H}\right) \geq \bar{r}_{L}
$$


where $\bar{r}_{L}=R_{L}\left(p_{L}^{E}, p_{H}^{E}\right)$. Therefore, Pareto efficiency can be characterized by the equality of the Marginal Rates of Substitution between the two types:

$$
\operatorname{MRS}_{L}\left(p_{L}^{E}, p_{H}^{E}\right)=M R S_{H}\left(p_{L}^{E}, p_{H}^{E}\right)
$$

where $M R S_{i}\left(p_{L}, p_{H}\right)=-\left(\partial R_{i} / \partial p_{L}\right) /\left(\partial R_{i} / \partial p_{H}\right)$ is the marginal rate of substitution of $p_{H}$ for $p_{L}$.

Figure 2 represents the set of Pareto efficient allocations. There is an infinite mass continuum of efficient price distributions, and only a small fraction (i.e. a finite mass continuum) of which dominates the Non-Cooperative Nash Equilibrium. The efficient allocation curve never intersects the unconstrained Best response functions meaning that, without a coordination policy, every country has an incentive to deviate from any efficient price distribution by lowering its own price. In fact, or all $i \in\{L, H\}$,

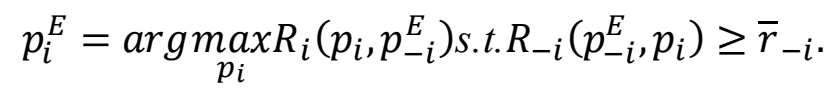

Since $R_{-i}\left(p_{-i}^{E}, p_{i}\right)$ increases with $p_{i}$, the constraint $R_{-i}\left(p_{-i}^{E}, p_{i}\right) \geq \bar{r}_{-i}$ requires $p_{i}$ to be greater than a certain level. So, $p_{i}^{E} \geq \operatorname{argmax}_{p_{i}} R_{i}\left(p_{i}, p_{-i}^{E}\right)$, and because the constraint binds in a Pareto's problem, we get the following with strict inequality

$$
p_{i}^{E}>P_{i}^{0}\left(p_{-i}^{E}\right)
$$

Figure A 2: Efficient Price Distributions and Unconstrained Best Response Functions

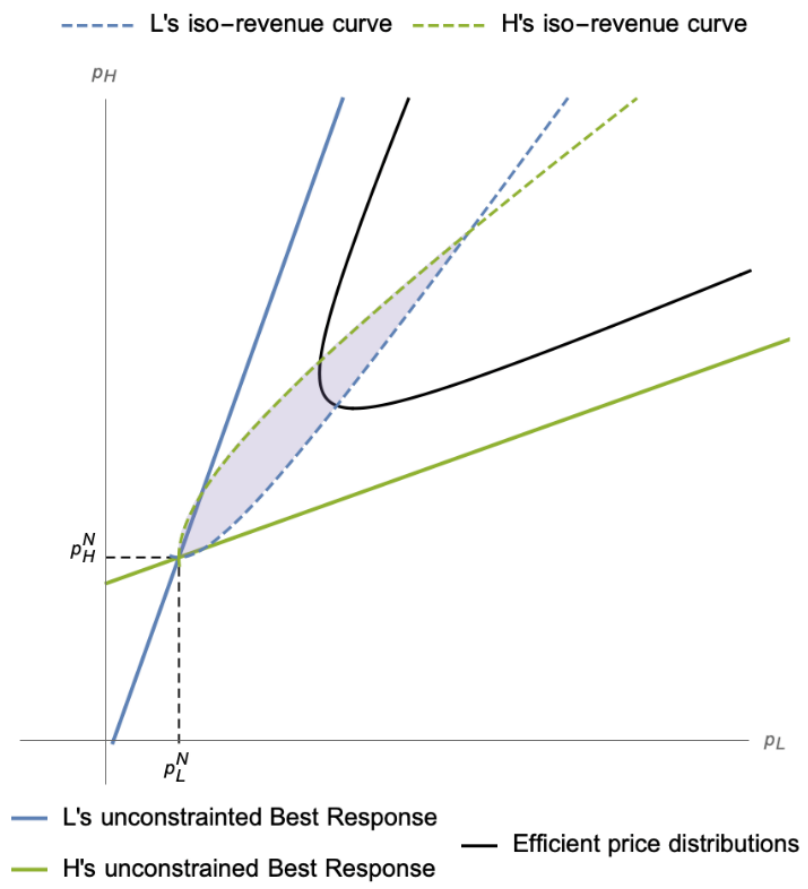


Lemma 1 (Implementability condition). A Pareto efficient price distribution $\left(p_{L}^{E}, p_{H}^{E}\right)$ with corresponding quantities $\left(q_{L}^{E}, q_{H}^{E}\right)$ is achievable by a Cooperative Nash Equilibrium with an appropriate minimum price $P_{\min }$ and maximum quota $q_{\max }$ if and only if countries with larger quantities charge higher prices. And then, we have $q_{\max }=\max \left\{q_{L}^{E}, q_{H}^{E}\right\}$ and $p_{\min }=$ $\min \left\{p_{L}^{E}, p_{H}^{E}\right\}$.

Proof. First, if there is a country type, say $\hat{\imath}$ such that $\hat{\imath}$ has the lowest quantity and the highest price, that is, $q_{\hat{\imath}}^{E}<q_{-\hat{\imath}}$ and $p_{\hat{\imath}}^{E}>p_{-\hat{\imath}}^{E}$, then for any Cooperative Nash Equilibrium that reach $\left(p_{L}^{E}, p_{H}^{E}\right)$ the minimum price constraint and the maximum quota constraint would not be binding the the $\hat{\imath}$ type. It could then benefit from deviating from $P_{\hat{\imath}}^{E}$ according to (12).

Now, suppose that countries with the largest quantity charge the highest price and set $q_{\max }=$ $\max \left\{q_{L}^{E}, q_{H}^{E}\right\}$ and $p_{\text {min }}=\min \left\{p_{L}^{E}, p_{H}^{E}\right\}$. Countries with the lowest price (resp. largest quantity) would like to lower their price but could not because of the minimum price (resp. maximum quota) constraint. And, then we get a Cooperative Nash Equilibrium.

For any price distribution $\left(p_{L}, p_{H}\right)$ and corresponding quantity $\left(q_{L}, q_{H}\right)$, define $\Delta p \equiv p_{H}-$ $p_{L}$ and $\Delta q \equiv q_{H}-q_{L}$. We have

$$
\begin{aligned}
\Delta q \Delta p & \Leftrightarrow\left\{\begin{array}{c}
\Delta q \geq 0 \text { and } \Delta p \geq 0 \\
\text { or } \\
\Delta q \leq 0 \text { and } \Delta p \leq 0
\end{array}\right. \\
& \Leftrightarrow\left\{\begin{array}{c}
v_{H}-v_{L}-(1+\delta) \Delta p \geq 0 \text { and } \Delta p \geq 0 \\
\text { or } \\
v_{H}-v_{L}-(1+\delta) \Delta p \leq 0 \text { and } \Delta \leq \geq 0
\end{array}\right. \\
& \left\{\begin{array}{l}
\Delta p \leq \frac{v_{H}-v_{L}}{1+\delta} \text { and } \Delta p \geq 0 \\
\Delta p \geq \frac{v_{H}-v_{L}}{1+\delta} \text { and } \Delta p \leq 0
\end{array}\right.
\end{aligned}
$$

Thus, since $v_{H}-v_{L}>0, \Delta q \Delta p \geq 0$ is equivalent to

$$
0 \leq p_{H}-p_{L} \leq \frac{v_{H}-v_{L}}{1+\delta}
$$

So, according to Lemma 1, a Pareto efficient price distribution $\left(p_{L}^{E}, p_{H}^{E}\right)$ can be reached by a Cooperative Nash Equilibrium if and only if $\left(p_{L}^{E}, p_{H}^{E}\right)$ satisfies (13).

Countries will be willing to cooperate for a Pareto efficient outcome only if it provides them with a higher revenue than the Non-Cooperative situation. So, we need to find out whether it is possible to achieve, through out a Cooperative Nash Equilibrium, a Pareto efficient allocation that is welfare improving for both types as compared to the NonCooperative scenario. 
For this purpose, define by $\left(\hat{p}_{L}, \hat{p}_{H}\right)$ a price distribution that provides each country with the same revenue as the Non-Cooperative Nash Equilibrium with $\left(\hat{p}_{L}, \hat{p}_{H}\right) \neq\left(p_{L}^{N}, p_{H}^{N}\right)$. $\left(\hat{p}_{L}, \hat{p}_{H}\right)$ exists and is unique ${ }^{16}$ and $M R S_{L}\left(\hat{p}_{L}, \hat{p}_{H}\right)>M R S_{H}\left(\hat{p}_{L}, \hat{p}_{H}\right)$ since $\operatorname{MRS}_{L}\left(p_{L}^{N}, p_{H}^{N}\right)<$ $M R S_{H}\left(p_{L}^{N}, p_{H}^{N}\right)$ (see Figure 4). Now consider, the Pareto efficient price distribution $\left(\hat{p}_{L}^{E}, \hat{p}_{H}^{E}\right)$ defined as a convex combination of $\left(\hat{p}_{L}, \hat{p}_{H}\right)$ and $\left(p_{L}^{N}, p_{H}^{N}\right)$, that is,

$$
\left(\hat{p}_{L}^{E}, \hat{p}_{H}^{E}\right)=\alpha\left(p_{L}^{N}, p_{H}^{N}\right)+(1-\alpha)\left(\hat{p}_{L}, \hat{p}_{H}\right)
$$

where $\alpha \in(0,1)$ is uniquely defined by $\operatorname{MRS}_{L}\left(\hat{p}_{L}^{E}, \hat{p}_{H}^{E}\right)=M R S_{H}\left(\hat{p}_{L}^{E}, \hat{p}_{H}^{E}\right)$. Clearly, $\left(\hat{p}_{L}^{E}, \hat{p}_{H}^{E}\right)$ is a Pareto improvement of the Non-Cooperative Equilibrium. Moreover, we know that the Non-Cooperative Equilibrium price $\left(p_{L}^{N}, p_{H}^{N}\right)$ satisfies (13). So, the efficient price distribution $\left(\hat{p}_{L}^{E}, \hat{p}_{H}^{E}\right)$ can be achieved by a Cooperative Nash Equilibrium if $\left(\hat{p}_{L}, \hat{p}_{H}\right)$ satisfies (13).

Lemma 2. $H$-type countries benefit more (or lose less) from an increase in a common price, while they benefit less (or lose more) from a decrease in a common quantity, i.e,

$$
\frac{\partial R_{L}(p, p)}{\partial p}<\frac{\partial R_{H}(p, p)}{\partial p} \text { and } \frac{\partial R_{L}\left(p, p_{H}(p)\right)}{\partial p}>\frac{\partial R_{H}\left(p, p_{H}(p)\right)}{\partial p}
$$

where $p_{H}(p)$ is defined by $q_{L}\left(p, p_{H}(p)\right)=q_{H}\left(p, p_{H}(p)\right)$.

Proof. The first inequality is easily derivable from the definition of $R_{L}\left(p_{L}, p_{H}\right)$ and $R_{H}\left(p_{L}, p_{H}\right)$ :

$$
\frac{d R_{H}(p, p)}{d p}=v_{H}-2 p>v_{L}-2 p=\frac{d R_{L}(p, p)}{d p} .
$$

To show the second inequality, we first derive an expression for $p_{H}(p)$ from $q_{L}\left(p, p_{H}(p)\right)=q_{H}\left(p, p_{H}(p)\right)$, which is $p_{H}(p)=p+\frac{v_{H}-v_{L}}{1+\delta}$. And after some algebra we get

$$
\frac{d R_{L}\left(p, p+\frac{v_{H}-v_{L}}{1+\delta}\right)}{d p}-\frac{d R_{H}\left(p, p+\frac{v_{H}-v_{L}}{1+\delta}\right)}{d p}=\frac{v_{H}-v_{L}}{1+\delta}>0
$$

Proposition 2. A Pareto efficient Cooperative Nash Equilibrium that provides all countries with higher revenues than the Non-Cooperative Nash Equilibrium exists.

${ }^{16}$ The existence of $\left(\hat{p}_{L}, \hat{p}_{H}\right)$ is guaranteed by

$$
\lim _{p_{L} \rightarrow \infty} M R S_{L}\left(p_{L}, p_{H}\right)=\lim _{p_{L} \rightarrow \infty} \frac{2 \partial q_{L} / \partial p_{L}}{\partial q_{L} / \partial p_{H}}>\lim _{p_{L} \rightarrow \infty} \frac{\partial q_{H} / p_{L}}{2 \partial q_{H} / \partial p_{H}}=\lim _{p_{H} \rightarrow \infty} M R S_{H}\left(p_{L}, p_{H}\right) .
$$

$\left(\hat{p}_{L}, \hat{p}_{H}\right)$ is unique because $L$ 's iso-revenue curve is convex while the one of $H$ is concave. 
Proof. From the previous analysis, it suffices to show that the price distribution $\left(\hat{p}_{L}, \hat{p}_{H}\right)$ that provides each country with the same revenue as the Non-Cooperative Nash Equilibrium satisfies

$$
0 \leq \hat{p}_{H}-\hat{p}_{L} \leq \frac{v_{H}-v_{L}}{1+\delta}
$$

First, note that $\hat{p}_{H}>P_{H}^{0}\left(\hat{p}_{L}\right)$ and $\hat{p}_{L}>P_{L}^{0}\left(\hat{p}_{H}\right)$ because indifference curves intersect with the corresponding best response line only once.

\section{First step:}

Suppose, by contradiction, that $\hat{p}_{H}-\hat{p}_{L}<0$ and consider the Cooperative Nash Equilibrium defined by $p_{\text {min }}=\hat{p}_{L}$ and $q_{\text {max }}$ is high enough, so that, the quota constraints do not bind. In this equilibrium the minimum price constraint binds for each type and the $L$-types earn more revenue as compare to the Non-Cooperative Nash Equilibrium while the $H$-types earn less:

$$
R_{L}\left(p_{\min }, p_{\min }\right)>R_{L}\left(p_{L}^{N}, p_{H}^{N}\right) \text { and } R_{H}\left(p_{\min }, p_{\min }\right)<R_{H}\left(p_{L}^{N}, p_{H}^{N}\right)
$$

That is impossible because $R_{L}\left(p_{H}^{N}, p_{H}^{N}\right)<R_{L}\left(p_{L}^{N}, p_{H}^{N}\right)$ and $R_{H}\left(p_{H}^{N}, p_{H}^{N}\right)>R_{H}\left(p_{L}^{N}, p_{H}^{N}\right)$ and $R_{H}(p, p)$ grows faster than $R_{L}(p, p)$ according to Lemma 2 . Therefore $0 \leq \hat{p}_{H}-\hat{p}_{L}$

\section{$\underline{\text { Second step: }}$}

Define by $\left(\hat{q}_{L}, \hat{q}_{H}\right)$ the corresponding quantities for $\left(\hat{p}_{L}, \hat{p}_{H}\right)$. Suppose, by contradiction, that $\hat{p}_{H}-\hat{p}_{L}>\frac{v_{H}-v_{L}}{1+\delta}$ (which means that $\hat{q}_{L}>\hat{q}_{H}$ ) and consider the Cooperative Nash Equilibrium defined by $q_{\max }=\hat{q}_{H}$ and $p_{\min }$ low enough, so that, the minimum price constraints become irrelevant. In this equilibrium the maximum quota constraint binds for each type and the $H$-types earn more revenue as compare to the Non-Cooperative Nash Equilibrium while the $L$-types earn less:

$$
R_{L}\left(p_{L}^{C}, p_{H}^{C}\right)<R_{L}\left(p_{L}^{N}, p_{H}^{N}\right) \text { and } R_{H}\left(p_{L}^{C}, p_{L}^{C}\right)>R_{H}\left(p_{L}^{N}, p_{H}^{N}\right)
$$

where $\left(p_{L}^{C}, p_{H}^{C}\right)$ is the cooperative price distribution with $q_{\max }=\hat{q}_{H}$. Since quantities are identical in this equilibrium, we must have $p_{H}^{C}=P_{L}^{C}+\frac{v_{H^{-}} v_{L}}{1+\delta}$.

Now, note that $p_{L}^{N}+\left(v_{H}-v_{L}\right) /(1+\delta)>p_{H}^{N}$ because the $q_{H}^{N}>q_{L}^{N}$. Therefore, Equation (14) is impossible because $R_{L}\left(p_{L}^{N}, p_{L}^{N}+\left(v_{H}-v_{L}\right) /(1+\delta)\right)>R_{L}\left(p_{L}^{N}, p_{H}^{N}\right)$ and

$R_{H}\left(p_{L}^{N}, p_{L}^{N}+\left(v_{H}-v_{L}\right) /(1+\delta)\right)<R_{H}\left(p_{L}^{N}, p_{H}^{N}\right)$ and $R_{L}\left(p, p+\left(v_{H}-v_{L}\right) /(1+\delta)\right)$ grows faster than $R_{H}\left(p, p+\left(v_{H}-v_{L}\right) /(1+\delta)\right)$ according to Lemma 2 . Therefore

$$
\hat{p}_{H}-\hat{p}_{L} \leq \frac{v_{H}-v_{L}}{1+\delta}
$$


A simple graphical argument could help understand the rationale behind this result. Consider Figure 3 and notice that any point that lay between the blue line and the green line can be achieved by setting a combination of a minimum price and a maximum quota. Now, observe that the green line always passes above $\left(\hat{p}_{L}, \hat{p}_{H}\right)$ because otherwise, they would exist a maximum quota level for which high-demand countries would earn more revenue as compared to their revenue in a non-cooperative equilibrium while low-demand countries would earn less, which is impossible. Analogously, the blue line always lay below $\left(\hat{p}_{L}, \hat{p}_{H}\right) \cdot$ Now, since the set of efficient price distributions (black line on the graph) always passes through the purple area (representing feasible Pareto improvements of the non-cooperative equilibrium), it always exists an efficient distribution of prices profitable to all types that lay between the green line and the blue line. Therefore, the right combination of a minimum price and a maximum quota would guarantee an efficient outcome that is more beneficial to every type of country than the non-cooperative equilibrium.

\section{Figure A 3: Efficient Pareto Improvement of the Non-Cooperative Nash Equilibrium}

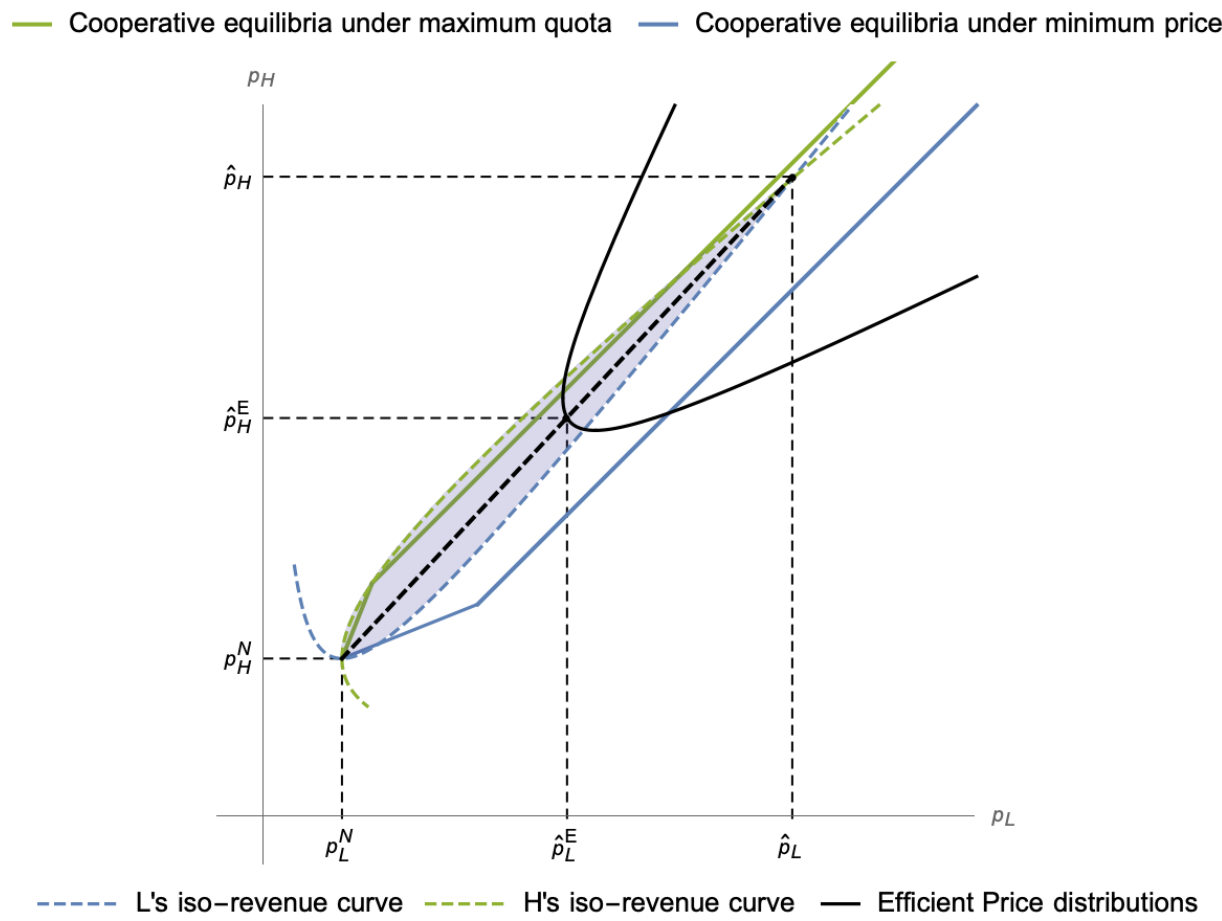




\section{REFERENCES}

Al-Hassan A, Burfisher, M., Chow, J., Ding, D., Di Vittorio, F., Kovtun, D., McIntyre, A., Ötker, I., Santoro, M., Shui, L. and K. Youssef, 2020, "Is the Whole Greater than the Sum of its Parts? Strengthening Caribbean Regional Integration," IMF Working Paper 2020/08

Bénassy-Quéré, A., Gobalraja, N. and A. Trannoy, 2007, “Tax and Public Goods Competition," Economic Policy, Vol. 22, No. 50

Bernadett, L., 2014, “The Parties to the Nauru Agreement's Vessel Day Scheme: Accounting for the Rare Success of an International Agreement."

Chai, J. and Goyal, R., 2008, "Tax Concessions and Foreign Direct Investment in the Eastern Caribbean Currency Union,” IMF Working Paper 08/257

Fanti, L. and L. Gori, 2011, “The dynamics of a Bertrand duopoly with differentiated products and bounded rational firms revisited," Munich Persona RePEc Archive, (33268)

Fisher, P. 2007. The Fiscal Consequences of Competition for Capital, W.E. Upjohn Institute for Employment Research, Kalamazoo. 21 Institute of Policy Analysis and Research (IPAR), 2011, East African Taxation Project: Rwanda Case Study, www.ipar.org

Friedman, J, 1983. Oligopoly Theory. Press Syndicate of the University of Cambridge

Klemm, A. and S. Van Parys, 2009, "Empirical Evidence on the Effects of Tax Incentives," IMF Working Paper 09/136, (Washington: International Monetary Fund).

James, S. and S. Van Parys, 2010, "The effectiveness of Tax Incentives in Attracting FDI: Evidence from the Tourism Sector in the Caribbean,"

Luger, M. and Bae, S. 2005, 'The Effectiveness of State Business Tax Incentive Programs: The Case of North Carolina.' Economic Development Quarterly, Vol. 19 (4)

McIntyre, M., 2017, “Tax Incentives: To use or Not To use?” In Unleashing Growth and Strengthening Resilience in the Caribbean, 101-122. International Monetary Fund, Washington DC

Martin, S., 2009, "Microfoundations for the Linear Demand Product Differentiation Model, with Applications," Institute for Research in the Behavioral, Eco nomic, and Management Sciences, (1221)

Xu, X, El-Ashram A. and J. Gold, 2015, “Too Much of A Good Thing? Prudent Management of Inflows under Economic Citizenship Programs," IMF Working Paper 15/93 
Yeeting, A., Weikard, H., Bailey, M., Ram-Bidesi, V. and S, Bush, "Stabilizing Cooperation through Pragmatic Tolerance: the Case of the Parties to the Nauru Agreement (PNA) Tuna Fishery," Reg Environ Change (2018) 18:885-897. 